Supporting Information

\title{
Copper(II) as a Platform for Probing the Steric Demand of Bulky $\beta$-Diketonates
}

Alec T. Larson ${ }^{\ddagger}$, Aaron S. Crossman $\ddagger$, Sebastian M. Krajewski, Michael P. Marshak* Department of Chemistry, University of Colorado Boulder, Colorado 80309, United States

michael.marshak@colorado.edu 


\section{Table of Contents}

Table S1: Compilation of bond angle data of various $\mathrm{Cu}^{\prime \prime} \beta$-diketonates 4

Table S2: Compilation of bond length data from various $\mathrm{Cu}^{\prime \prime} \beta$-diketonates. $\quad 5$

Figure S3: ${ }^{1} \mathrm{H}$ NMR spectrum of $\mathbf{1}$ in $\mathrm{CDCl}_{3}$. 6

$\begin{array}{ll}\text { Figure S4: IR spectrum of } \mathbf{1} \text { as a neat solid. } & 7\end{array}$

Figure S5: UV-Vis Spectrum of 1 in dichloromethane. 8

Figure S6: Cyclic voltammogram of $1 \quad 9$

Figure S7. UV-Vis spectrum of 2 in the presence of 2 equiv. $\mathrm{PPh}_{3}$ in THF. 10

Figure S8: Cyclic voltammogram of 2

Figure S9: Scan-rate variant cyclic voltammogram of 2

Figure S10: Stacked cyclic voltammogram of $\mathbf{2}$ (black trace), L2 (red trace), [K( $\left.\left.\mathrm{L}^{2}\right)\right] 2$ (blue trace) 13

Figure S11: ${ }^{1} \mathrm{H}$ NMR spectrum of $3 \quad 14$

Figure S12: IR spectrum of $3 \quad 15$

Figure S13: UV-Vis spectrum of $3 \quad 16$

Figure S14: UV-Vis spectrum of $3 \quad 17$

Figure S15: Cyclic voltammogram of $3 \quad 18$

Figure S16: ${ }^{1} \mathrm{H}$ NMR spectrum of $4 \quad 19$

Figure S17: IR spectrum of $4 \quad 20$

Figure S18: UV-Vis spectrum of 4

Figure S19: Cyclic voltammogram of $4 \quad 22$

Figure S20: ${ }^{1} \mathrm{H}$ NMR spectrum of 5

Figure S21: IR spectrum of 5

Figure S22: UV-Vis spectrum of 5

Figure S23: Cyclic voltammogram of 5

Figure S24: ${ }^{1} \mathrm{H}$ NMR spectrum of $6 \quad 27$

Figure S25: IR Spectrum of $6 \quad 28$

Figure S26: UV-Vis spectrum of $6 \quad 29$

Figure S27: Cyclic voltammogram of $6 \quad 30$

Figure S28: ${ }^{1} \mathrm{H}$ NMR of 7

Figure S29: ${ }^{13} \mathrm{C}$ NMR spectrum of $7 \quad 32$

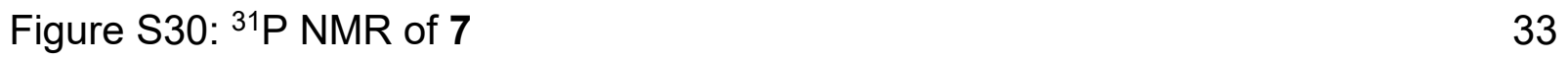


Figure S31: IR spectrum of $7 \quad 34$

$\begin{array}{ll}\text { Figure S32: UV-Vis spectrum of } 7 & 35\end{array}$

Table S33: Results of the initial catalytic screen using 2 as a catalyst 36

$\begin{array}{ll}\text { Results of general catalytic screen } & 37\end{array}$

Table S34: Results of the general catalytic screens using fixed conditions while varying the catalyst.

Cyclic Voltammograms of Parent Copper(II) $\beta$-Diketonate Complexes 38

Figure S35: Cyclic voltammogram of $\mathrm{Cu}(\mathrm{acac})_{2} \quad 38$

Figure S36: Cyclic voltammogram of $\mathrm{Cu}(\mathrm{dpm})_{2} \quad 39$

Figure S37: Cyclic voltammogram of $\mathrm{Cu}(\mathrm{dbm})_{2} \quad 40$

Figure S38: Cyclic voltammogram of $\mathrm{Cu}(\mathrm{bzac})_{2}$

X-Ray Crystallographic Details 42

Figure S39: Thermal ellipsoid plot of $1 \quad 42$

Figure S40: Thermal ellipsoid plot of $3 \quad 43$

Figure S41: Thermal ellipsoid plot of $4 \quad 44$

Figure S42: Thermal ellipsoid plot of $5 \quad 45$

Figure S43: Thermal ellipsoid plot of $6 \quad 46$

Figure S44: Thermal ellipsoid plot of $7 \quad 47$

Figure S45. Thermal ellipsoid plot of $\left[K\left(L^{2}\right)\right] 2$

Crystallographic Details 49

$\begin{array}{ll}\text { Crystal Tables } & 50\end{array}$ 
Table S1: Compilation of bond angle data of various $\mathrm{Cu}^{\text {II }} \beta$-diketonates. Subset of the determined angles from the crystal structures (with error).

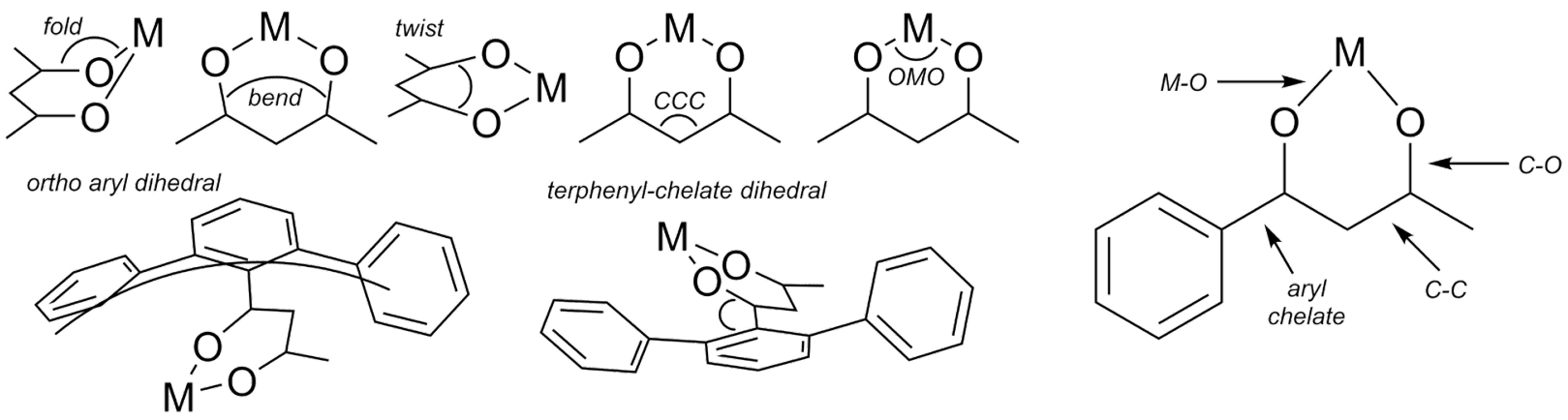

\begin{tabular}{|c|c|c|c|c|c|c|c|}
\hline \multirow[b]{2}{*}{ Complex } & \multicolumn{7}{|c|}{ Angles $\left({ }^{\circ}\right)$} \\
\hline & Twist & Bend & Fold & OMO & CCC & $\begin{array}{l}\text { Ortho aryl } \\
\text { dihedral }\end{array}$ & $\begin{array}{l}\text { Aryl chelate } \\
\text { dihedral }\end{array}$ \\
\hline $\begin{array}{c}\mathrm{Cu}(\mathrm{acac})_{2} \\
(\mathrm{ACACCU} 01)\end{array}$ & $0.01(4)$ & $14.88(17)$ & $6.21(11)$ & $93.75(7)$ & $124.3(2)$ & -- & -- \\
\hline $\begin{array}{c}\mathrm{Cu}(\mathrm{bzac})_{2} \\
(\mathrm{CUBEAC01})\end{array}$ & $0.61(7)$ & $14.2(3)$ & $5.00(6)$ & $93.16(13)$ & $124.5(4)$ & -- & $14.79(18)$ \\
\hline $\begin{array}{c}\mathrm{Cu}(\mathrm{dbm})_{2} \\
(\mathrm{CUPROP} 01)\end{array}$ & $1.01(2)$ & $15.23(2)$ & $3.85(2)$ & $93.30(13)$ & $123.08(13)$ & -- & $\begin{array}{c}10.56(5) \\
3.81(5)\end{array}$ \\
\hline $\begin{array}{c}\mathrm{Cu}(\mathrm{dpm})_{2} \\
(\mathrm{DERNOD03})\end{array}$ & $0.10(5)$ & $13.5(3)$ & $1.61(14)$ & $92.80(10)$ & $124.1(3)$ & -- & -- \\
\hline 1 & $0.54(6)$ & $13.3(2)$ & $15.14(16)$ & $92.57(10)$ & 123.6(3) & -- & $\begin{array}{l}46.52(12), \\
37.86(12)\end{array}$ \\
\hline 2 & $0.50(3)$ & $14.08(15)$ & $2.75(9)$ & $93.18(6)$ & $123.56(18)$ & $121.34(7)$ & $78.54(7)$ \\
\hline 3 & $1.12(4)$ & $14.51(12)$ & $10.85(10)$ & $92.66(6)$ & $122.76(18)$ & $115.13(7)$ & $66.39(9)$ \\
\hline \multirow{2}{*}{4} & $0.87(3)$ & $14.23(11)$ & $2.10(9)$ & $93.35(5)$ & $123.28(10)$ & $133.20(13)$ & $70.78(6)$ \\
\hline & $0.08(3)$ & $14.13(10)$ & $6.55(10)$ & $93.45(4)$ & $123.42(10)$ & $133.79(5)$ & $66.31(6)$ \\
\hline \multirow{2}{*}{5} & $1.14(3)$ & $15.25(13)$ & $2.16(7)$ & $93.44(5)$ & $123.29(16)$ & $115.76(6)$ & $63.49(6)$ \\
\hline & $0.17(3)$ & $13.87(13)$ & $3.72(8)$ & $93.08(5)$ & $122.79(15)$ & $122.04(3)$ & $61.73(6)$ \\
\hline 6 & $0.11(6)$ & $15.5(3)$ & 10.71(17) & $93.27(11)$ & $122.5(3)$ & $128.7(13)$ & $66.50(13)$ \\
\hline \multirow{2}{*}{7} & $0.8(2)$ & 19.2(9) & $6.7(5)$ & $90.4(3)$ & $124.0(13)$ & $128.2(4)$ & $67.3(5)$ \\
\hline & $1.2(2)$ & $21.0(9)$ & $3.7(6)$ & $91.5(3)$ & $127.0(11)$ & $132.5(5)$ & $60.9(5)$ \\
\hline
\end{tabular}


Table S2: Compilation of bond length data from various $\mathrm{Cu}^{\text {Il }} \beta$-diketonates. Subset of the determined bond lengths from the crystal structures (with error).

\begin{tabular}{|c|c|c|c|c|}
\hline \multirow{2}{*}{ Complex } & \multicolumn{4}{|c|}{ Lengths $(\AA)$} \\
\hline & $\mathrm{M}-\mathrm{O}$ & $\mathrm{C}-\mathrm{O}$ & $\mathrm{C}-\mathrm{C}$ & Aryl-chelate \\
\hline $\begin{array}{c}\mathrm{Cu}(\mathrm{acac})_{2} \\
(\mathrm{ACACCU} 1)\end{array}$ & $\begin{array}{l}1.9268(16), \\
1.9227(16)\end{array}$ & $\begin{array}{l}1.276(3) \\
1.275(3)\end{array}$ & $\begin{array}{l}1.403(3) \\
1.402(3)\end{array}$ & -- \\
\hline $\begin{array}{c}\mathrm{Cu}(\mathrm{bzac})_{2} \\
(\mathrm{CUBEAC01})\end{array}$ & $\begin{array}{l}\text { 1.924(3), } \\
1.918(3)\end{array}$ & $\begin{array}{l}1.270(5), \\
1.269(5)\end{array}$ & $\begin{array}{l}1.400(6), \\
1.405(6)\end{array}$ & $1.501(6)$ \\
\hline $\begin{array}{c}\mathrm{Cu}(\mathrm{dbm})_{2} \\
(\mathrm{CUPROP} 01)\end{array}$ & $\begin{array}{l}1.907(4) \\
1.910(5)\end{array}$ & $\begin{array}{l}1.285(3) \\
1.260(2)\end{array}$ & $\begin{array}{l}1.397(3) \\
1.393(4)\end{array}$ & $\begin{array}{l}1.486(4) \\
1.494(3)\end{array}$ \\
\hline $\begin{array}{c}\mathrm{Cu}(\mathrm{dpm})_{2} \\
(\mathrm{DERNOD03})\end{array}$ & $\begin{array}{l}1.902(2) \\
1.891(2)\end{array}$ & $\begin{array}{l}1.273(3) \\
1.276(4)\end{array}$ & $\begin{array}{l}1.376(5), \\
1.395(5)\end{array}$ & -- \\
\hline 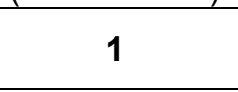 & $\begin{array}{l}1.906(2), \\
1.898(2)\end{array}$ & $\begin{array}{l}1.277(4), \\
1.282(4)\end{array}$ & $\begin{array}{l}1.394(4), \\
1.394(5)\end{array}$ & $\begin{array}{l}1.494(5), \\
1.490(4)\end{array}$ \\
\hline 2 & $\begin{array}{l}1.9074(13), \\
1.8972(15)\end{array}$ & $\begin{array}{l}1.271(2) \\
1.272(2)\end{array}$ & $\begin{array}{l}1.390(3), \\
1.398(3)\end{array}$ & $1.505(2)$ \\
\hline 3 & $\begin{array}{l}1.9093(13), \\
1.8962(14)\end{array}$ & $\begin{array}{l}\text { 1.271(2), } \\
1.275(2) \\
\end{array}$ & $\begin{array}{c}1.398(3) \\
1.395(2) \\
\end{array}$ & $1.508(2)$ \\
\hline \multirow{2}{*}{4} & $\begin{array}{l}1.8917(9), \\
1.9062(10)\end{array}$ & $\begin{array}{l}\text { 1.2816(15), } \\
1.2643(16)\end{array}$ & $\begin{array}{l}1.3877(18), \\
1.4063(19)\end{array}$ & $1.5040(18)$ \\
\hline & $\begin{array}{l}1.8874(9), \\
1.9156(9)\end{array}$ & $\begin{array}{l}\text { 1.2776(15), } \\
1.2699(16)\end{array}$ & $\begin{array}{l}\text { 1.3837(17), } \\
1.4048(18)\end{array}$ & $1.5010(17)$ \\
\hline \multirow{2}{*}{5} & $\begin{array}{l}1.8953(11), \\
1.9216(11)\end{array}$ & $\begin{array}{l}\text { 1.2742(19), } \\
1.2727(19)\end{array}$ & $\begin{array}{l}1.393(2) \\
1.405(2)\end{array}$ & $1.506(2)$ \\
\hline & $\begin{array}{l}\text { 1.8841(11), } \\
1.9207(11)\end{array}$ & $\begin{array}{l}\text { 1.2752(19), } \\
1.2777(19)\end{array}$ & $\begin{array}{l}1.395(2) \\
1.400(2)\end{array}$ & $1.500(2)$ \\
\hline 6 & $\begin{array}{c}1.897(3) \\
1.939(3) \\
\end{array}$ & $\begin{array}{c}1.282(4), \\
1.269(4) \\
\end{array}$ & $\begin{array}{l}1.389(5) \\
1.400(5)\end{array}$ & $1.499(5)$ \\
\hline \multirow{2}{*}{7} & $\begin{array}{l}2.058(7), \\
2.033(8)\end{array}$ & $\begin{array}{l}1.265(12), \\
1.255(11)\end{array}$ & $\begin{array}{l}1.390(14), \\
1.435(14)\end{array}$ & $1.531(15)$ \\
\hline & $\begin{array}{l}2.036(8), \\
2.037(7)\end{array}$ & $\begin{array}{l}1.290(12), \\
1.270(12)\end{array}$ & $\begin{array}{l}1.364(14), \\
1.393(14)\end{array}$ & $1.488(15)$ \\
\hline
\end{tabular}


${ }^{1} \mathrm{H}$ NMR $\left(400 \mathrm{MHz}, \mathrm{CDCl}_{3}\right) \delta 9.52,7.59,6.45,2.00,1.55$.

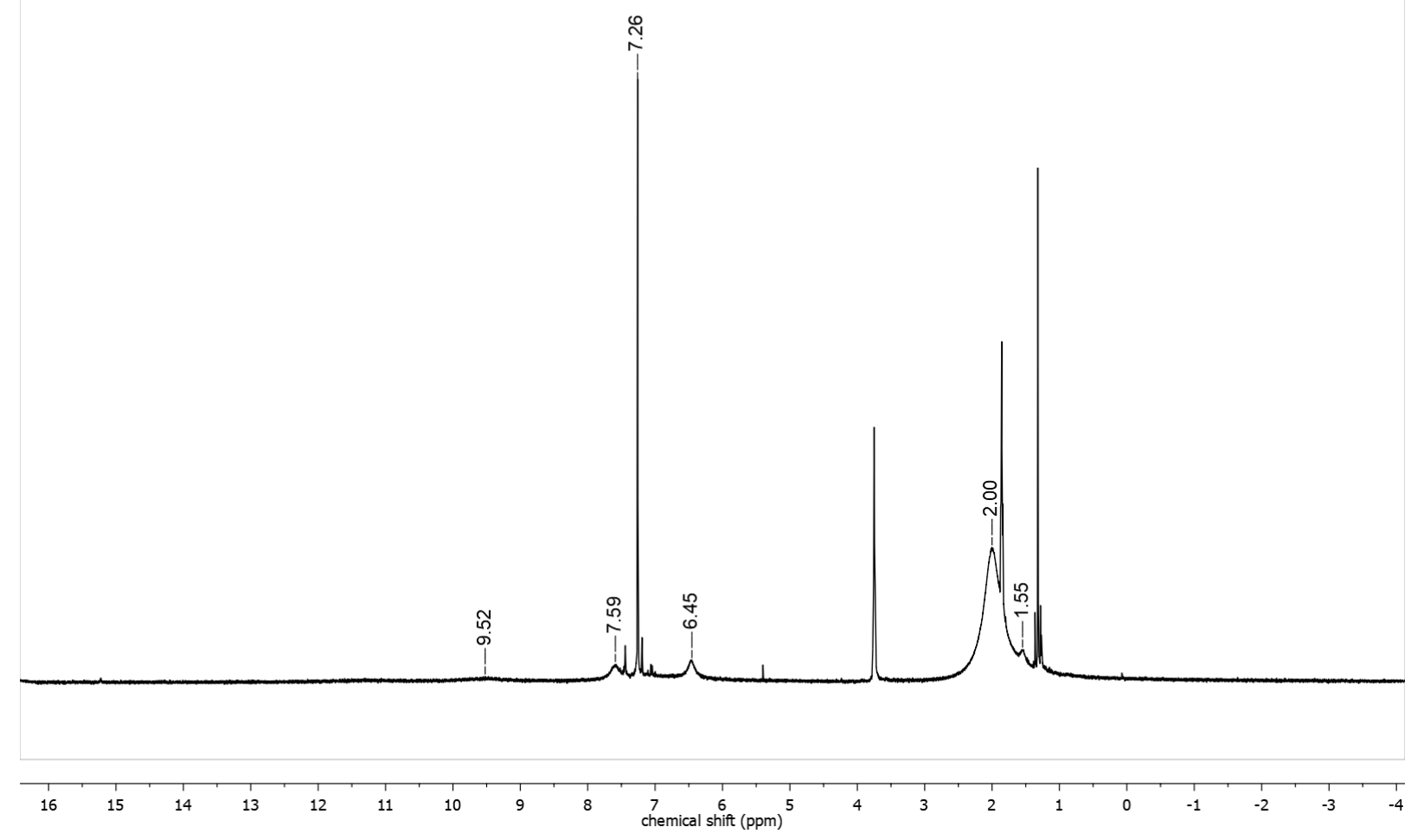

Figure S3: ${ }^{1} \mathrm{H}$ NMR spectrum of 1 in $\mathrm{CDCl}_{3}$. 


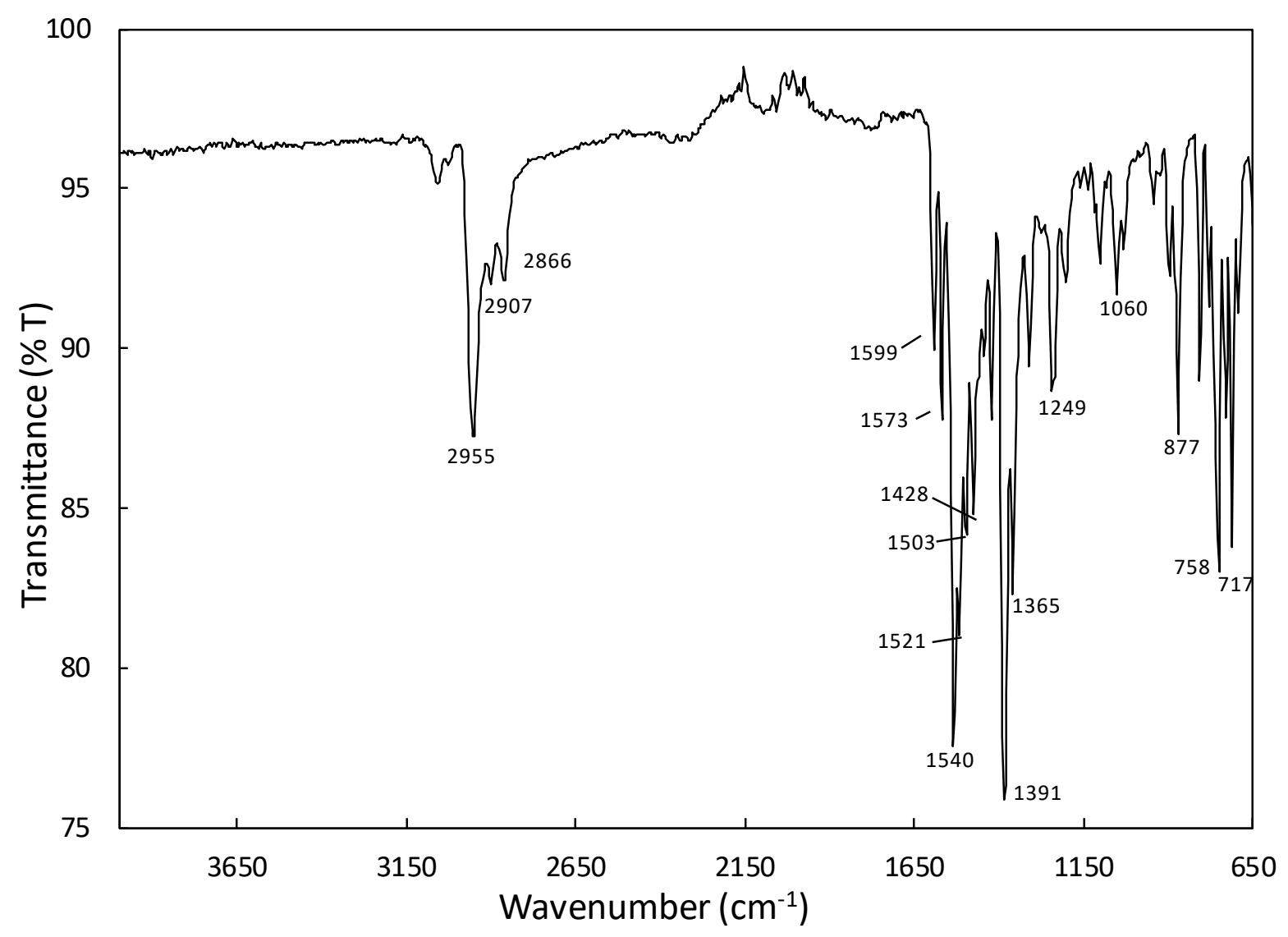

Figure S4: IR spectrum of 1 as a neat solid. 


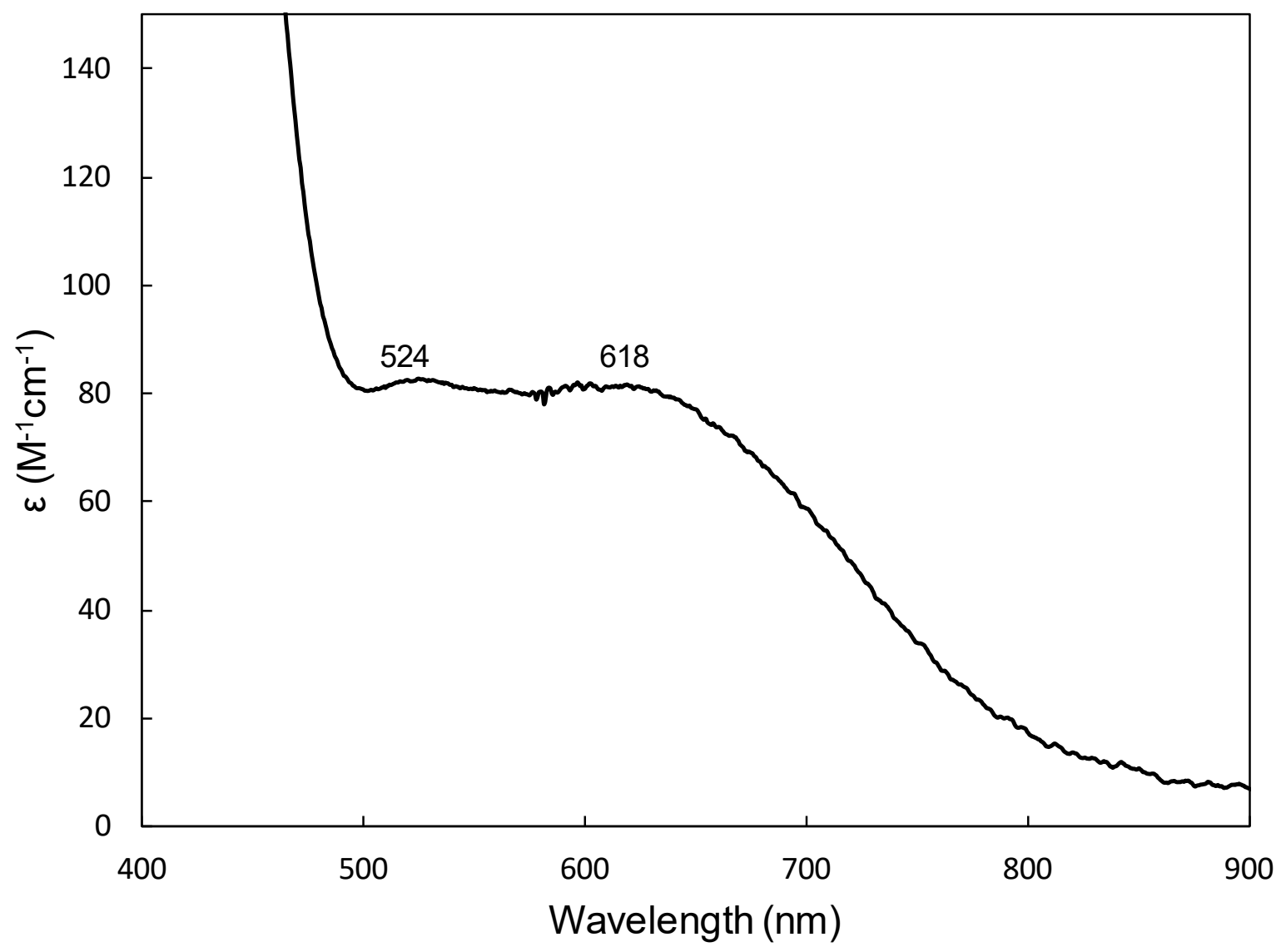

Figure S5: UV-Vis Spectrum of 1 in dichloromethane. 


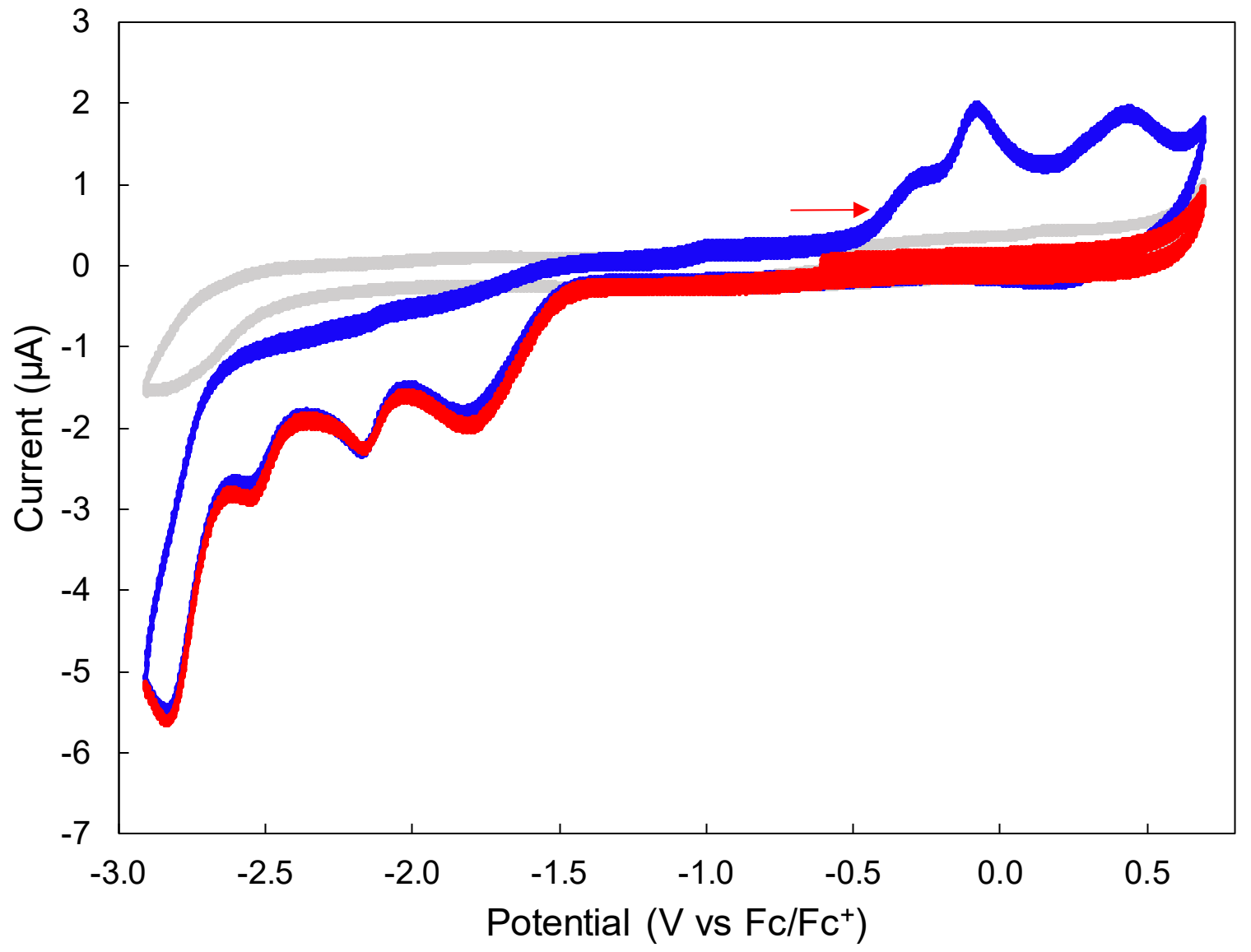

Figure S6: Cyclic voltammogram of 1 (0.1 M TBAPF 6 in THF, $5 \mathrm{mM}$ analyte concentration, $200 \mathrm{mV} / \mathrm{s}$ scan rate). The grey trace represents the solvent blank, the red trace is the initial scan, and the blue trace is the return scan immediately following the first. 


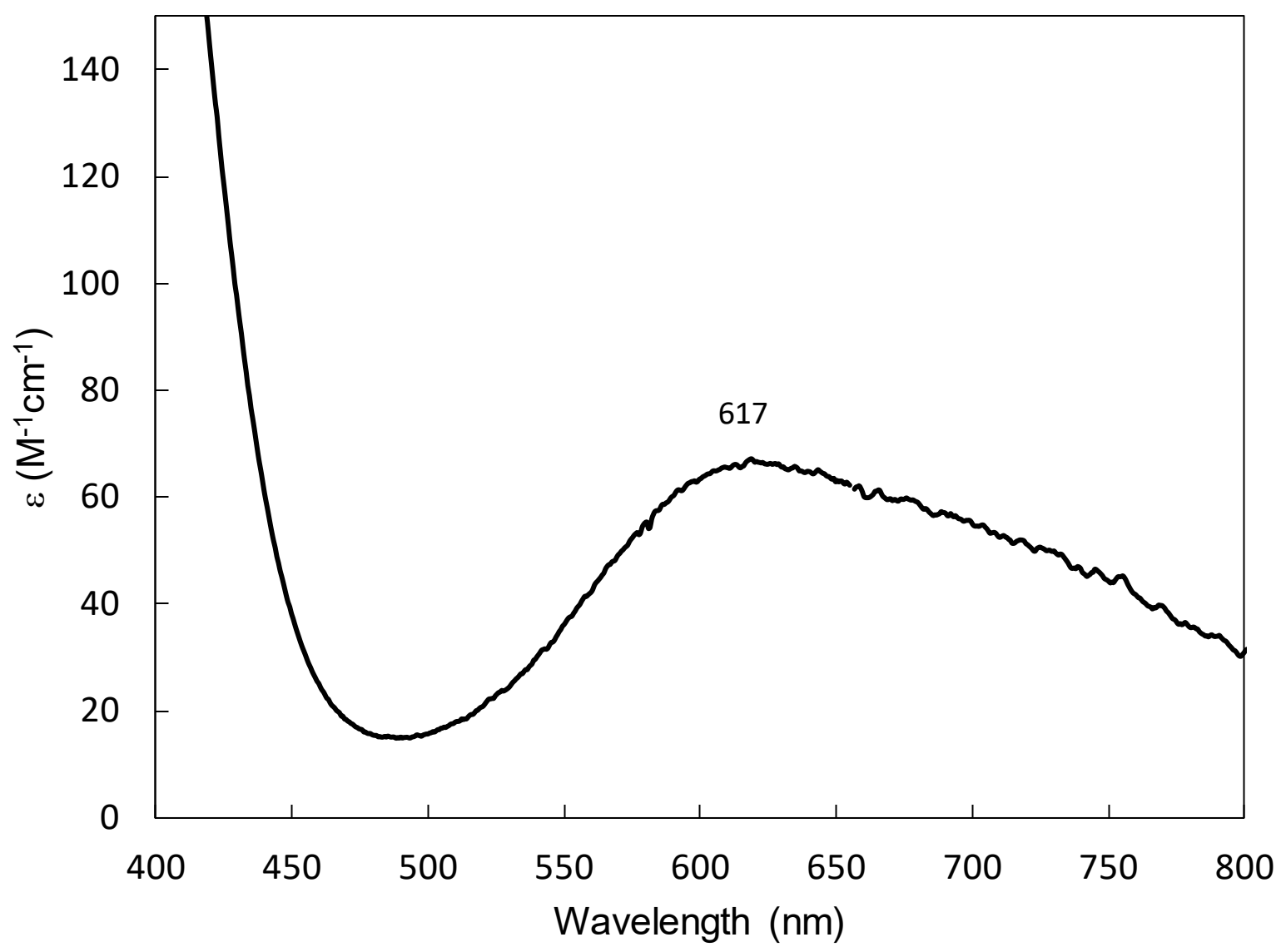

Figure S7. UV-Vis spectrum of 2 in the presence of 2 equiv. $\mathrm{PPh}_{3}$ in THF. 


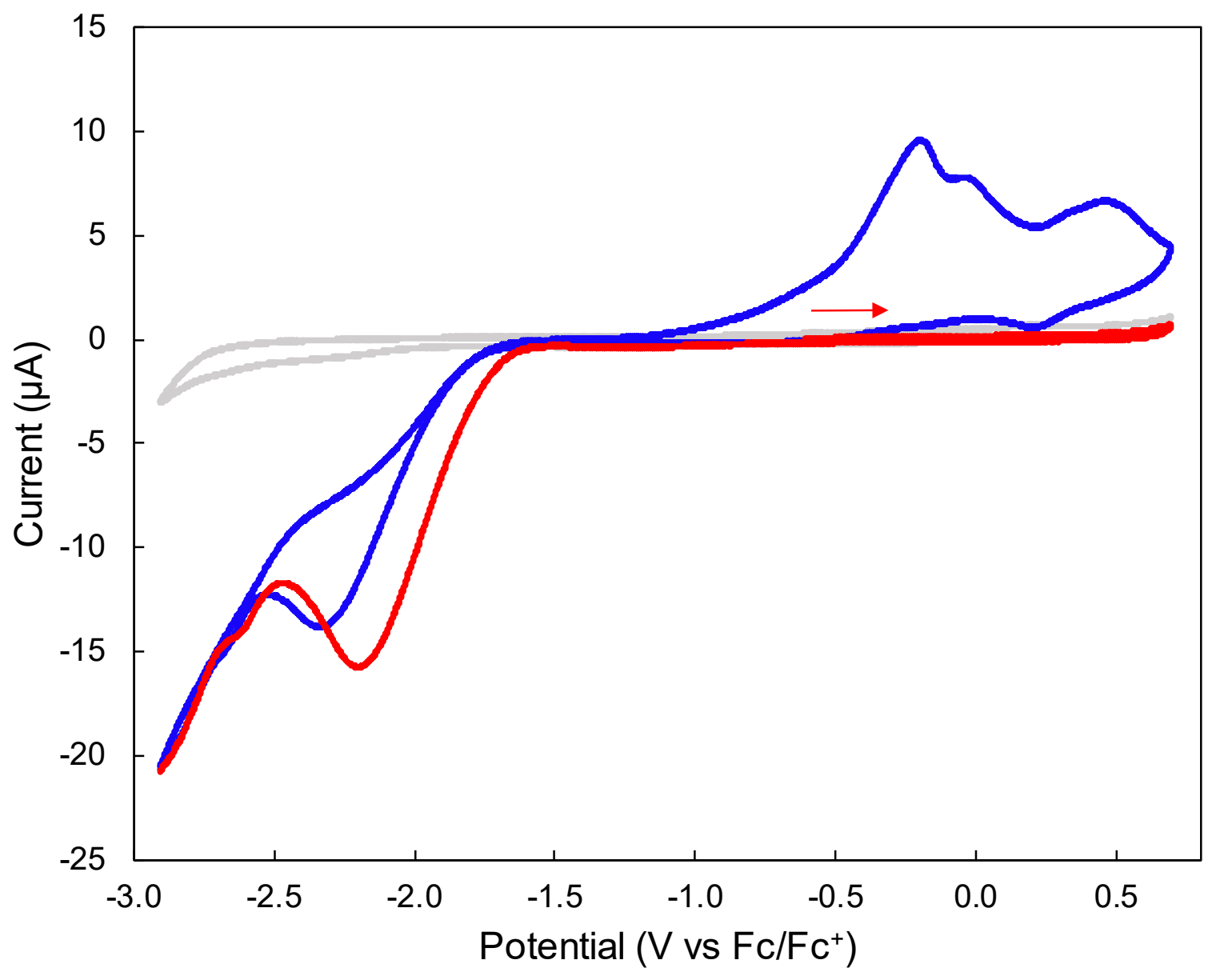

Figure S8: Cyclic voltammogram of 2 (0.1 $\mathrm{M} \mathrm{TBAPF}_{6}$ in THF, $5 \mathrm{mM}$ analyte concentration, $200 \mathrm{mV} / \mathrm{s}$ scan rate). The grey trace represents the solvent blank, the red trace is the initial scan, and the blue trace is the return scan immediately following the first. 


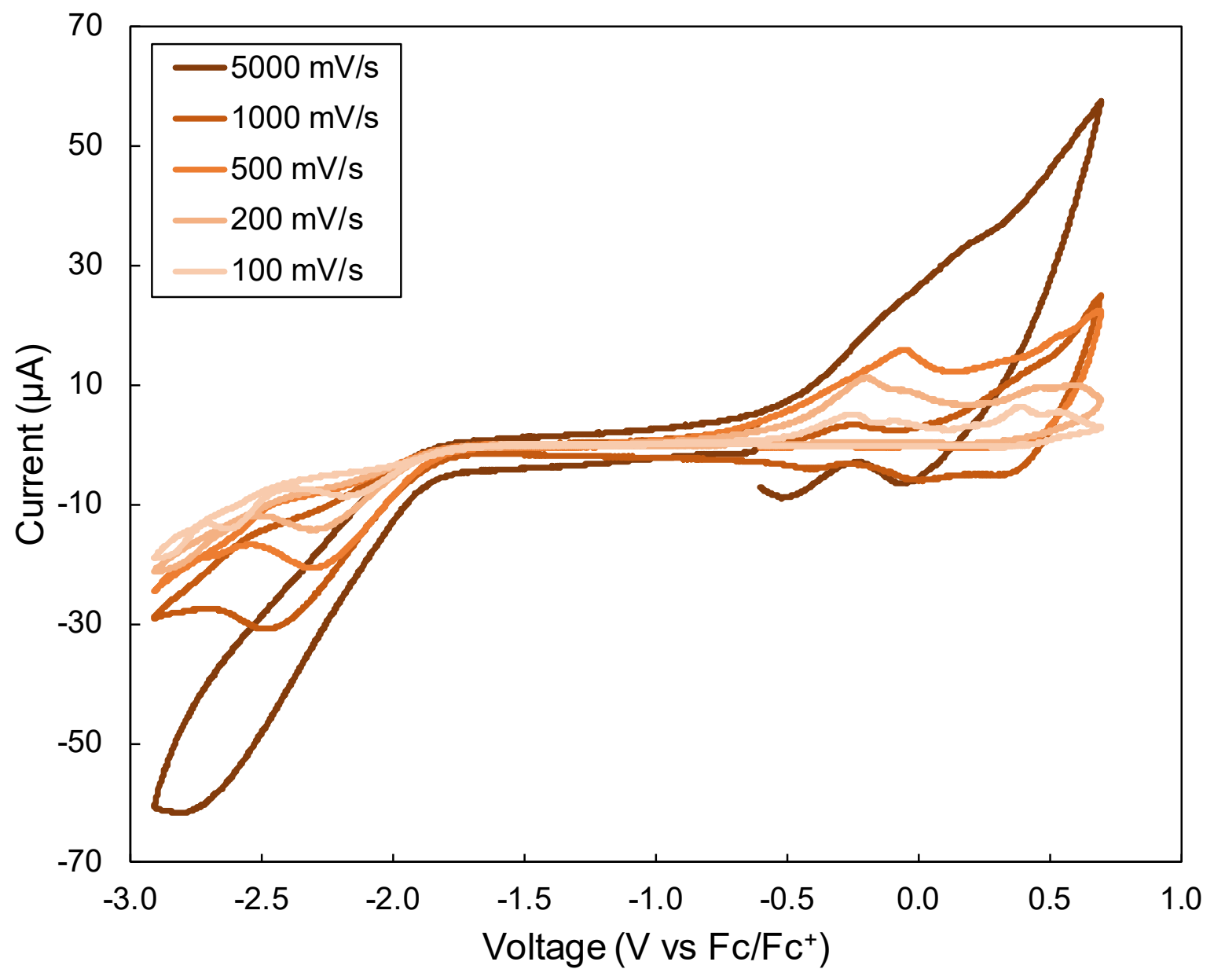

Figure S9: Scan-rate variant cyclic voltammogram of $2\left(0.1 \mathrm{M} \mathrm{TBAPF}_{6}, 5 \mathrm{mM}\right.$ analyte concentration). 


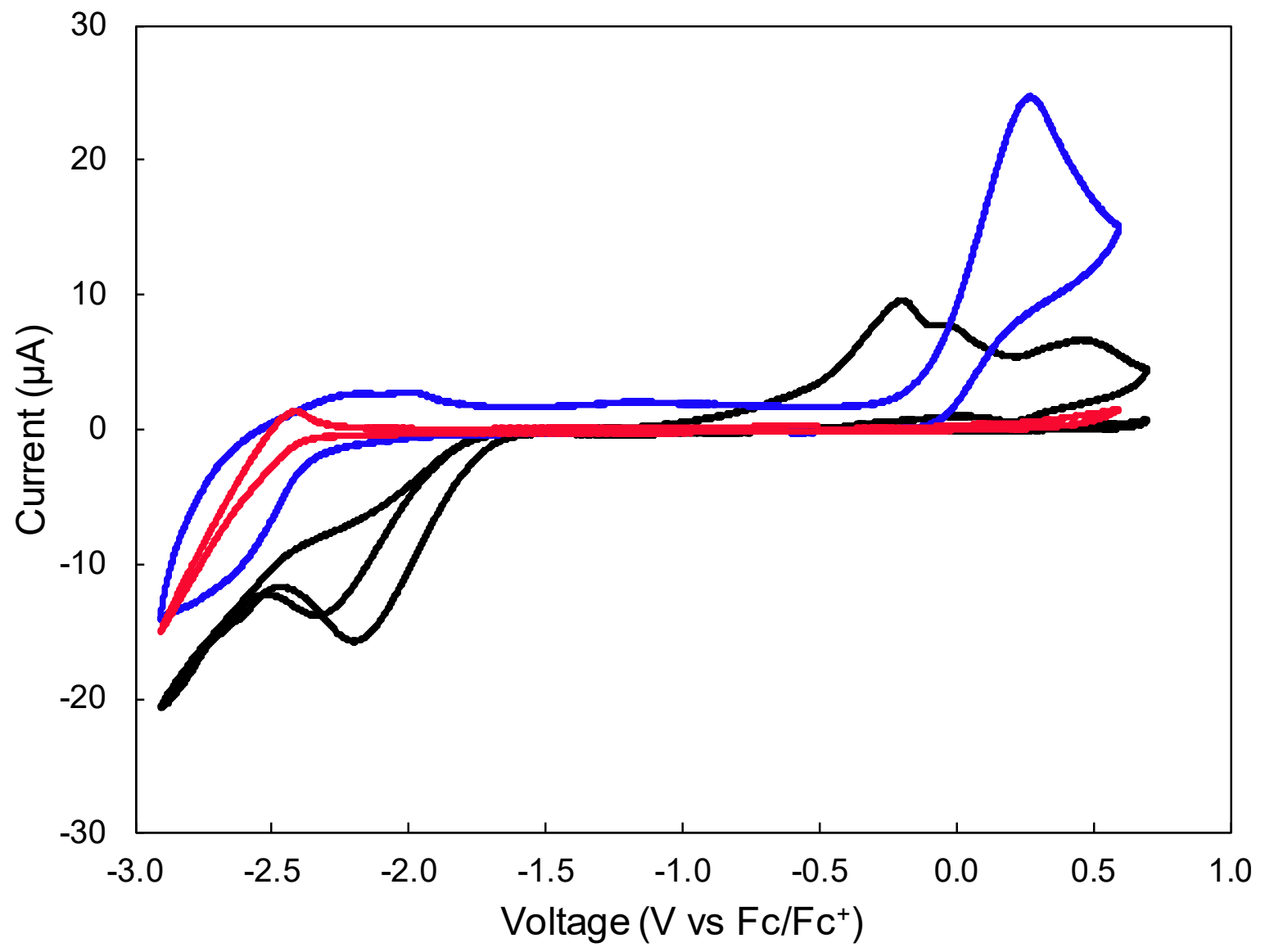

Figure S10: Stacked cyclic voltammogram of 2 (black trace), L2 (red trace), [K( $\left.\left.\mathbf{L}^{2}\right)\right] 2$ (blue trace) (0.1 M TBAPF 6 in THF, $5 \mathrm{mM}$ analyte concentration, $200 \mathrm{mV} / \mathrm{s}$ scan rate). 
${ }^{1} \mathrm{H}$ NMR $\left(400 \mathrm{MHz}, \mathrm{CDCl}_{3}\right) \delta 9.75,7.71,6.86,5.37,5.23,4.03,3.11,2.29,2.23,2.03,1.81,1.70$, 1.30 .

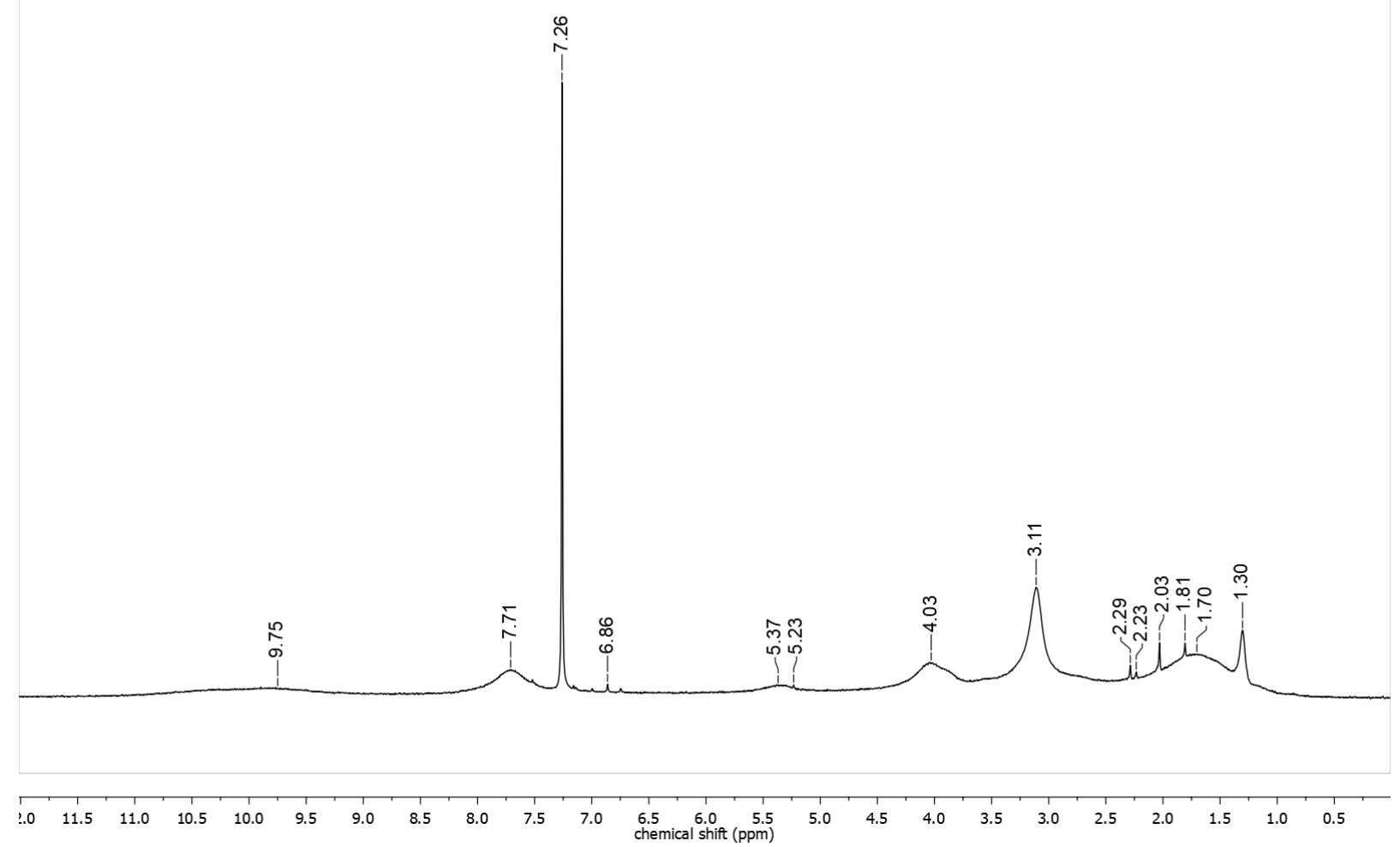

Figure $\mathrm{S} 11:{ }^{1} \mathrm{H}$ NMR spectrum of 3 in $\mathrm{CDCl}_{3}$. 


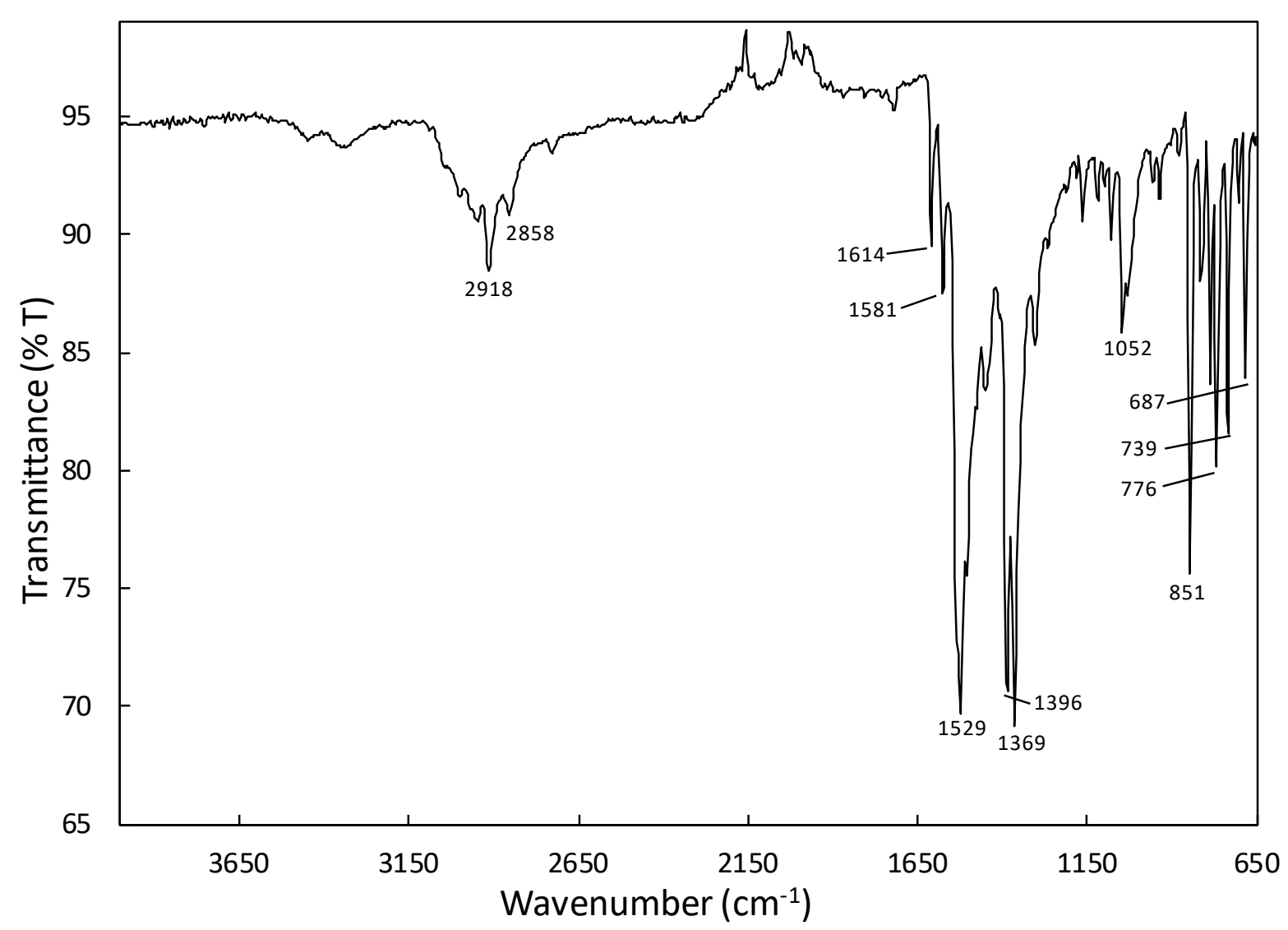

Figure S12: IR spectrum of $\mathbf{3}$ as a neat solid. 


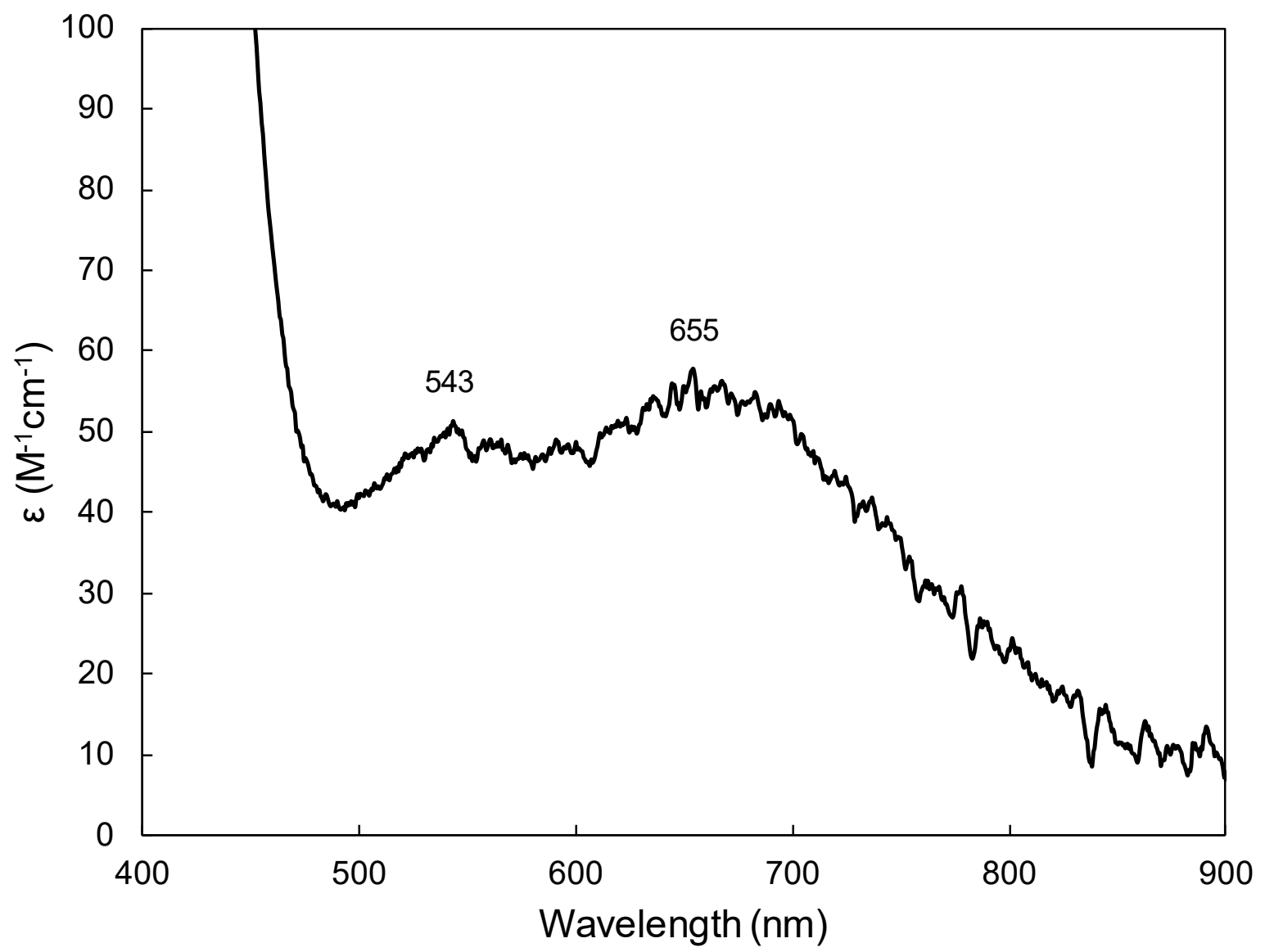

Figure S13: UV-Vis spectrum of $\mathbf{3}$ in dichloromethane. 


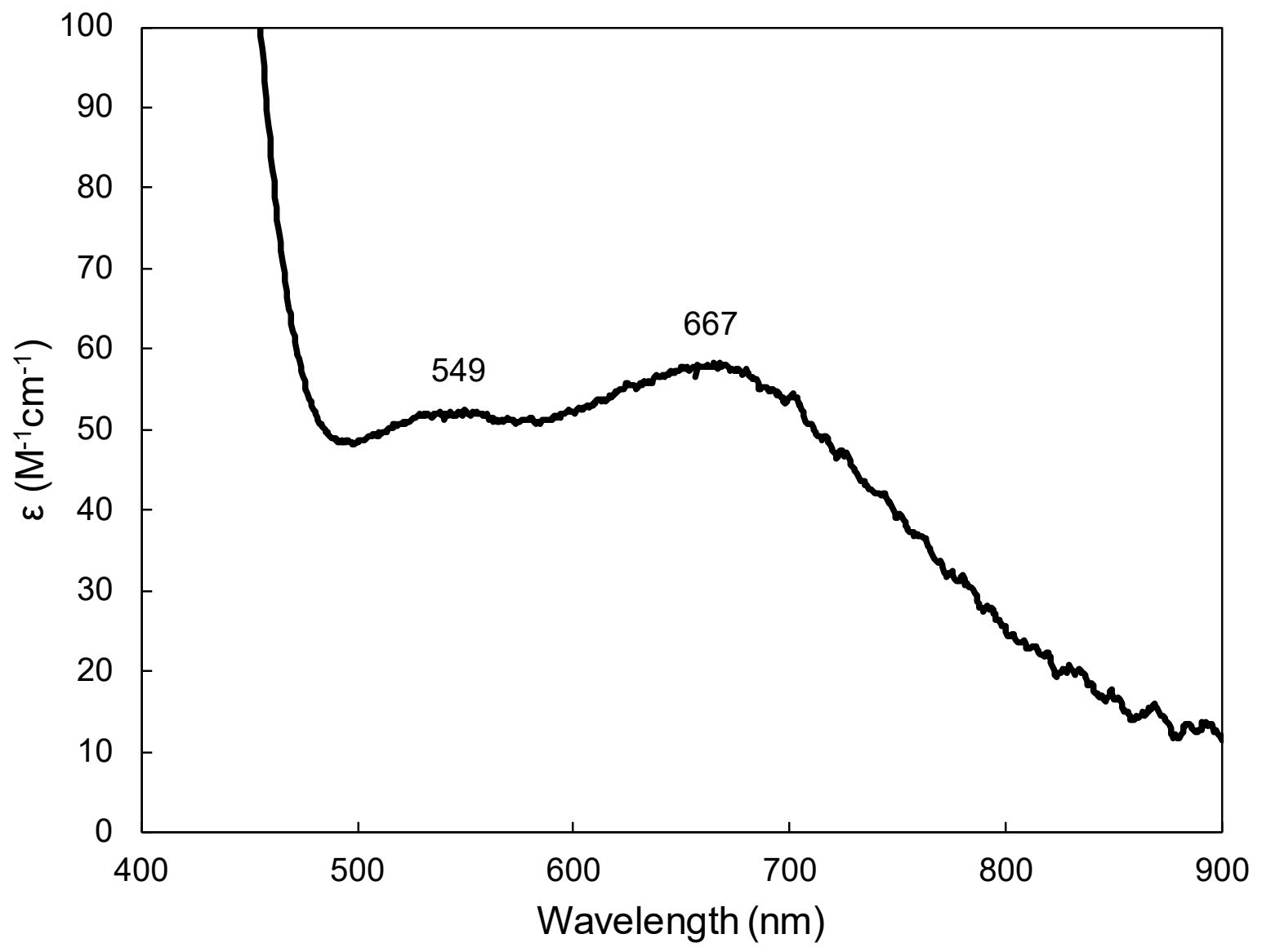

Figure S14: UV-Vis spectrum of $\mathbf{3}$ in chloroform. 


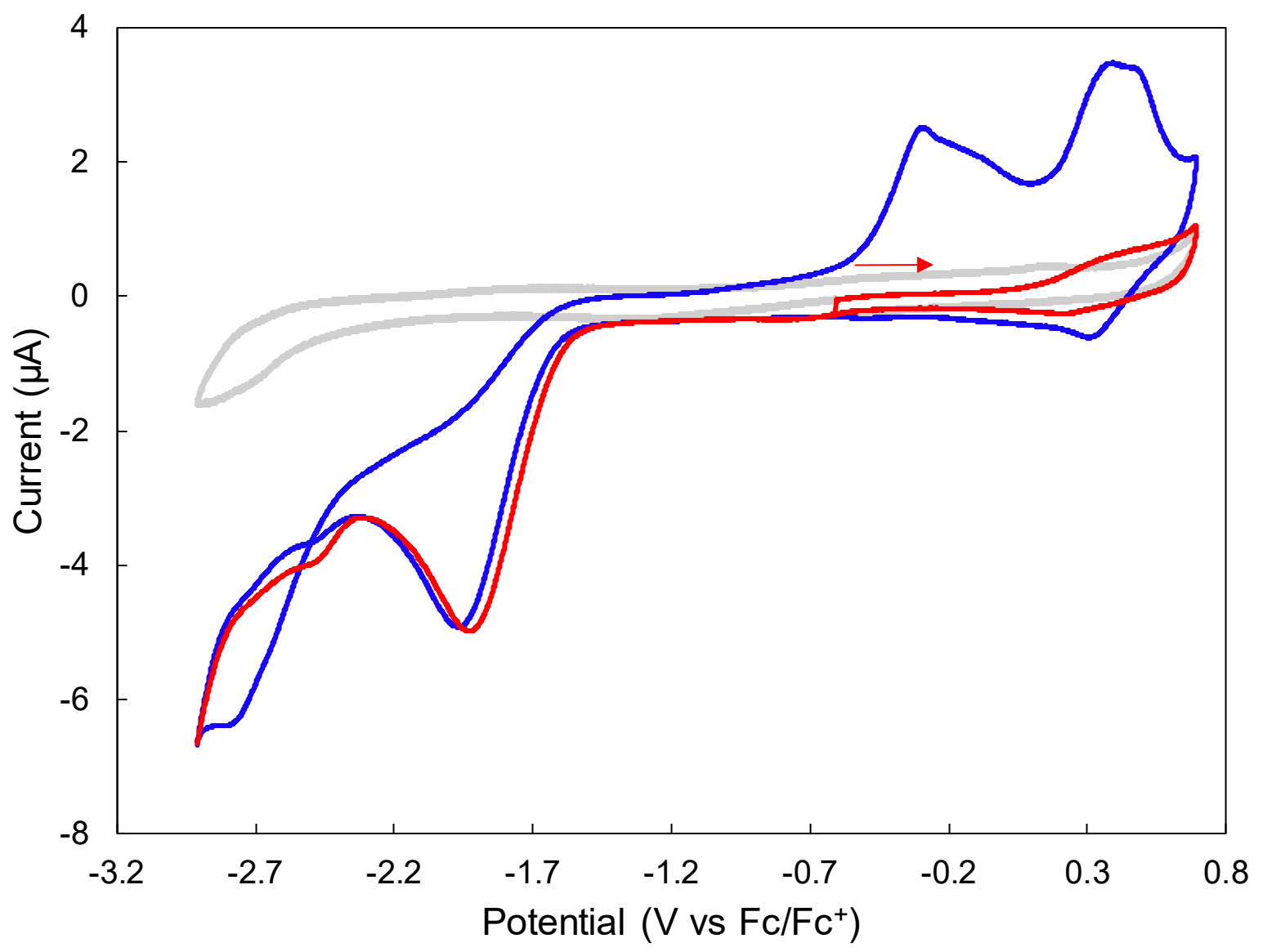

Figure S15: Cyclic voltammogram of 3 (0.1 $\mathrm{M} \mathrm{TBAPF}_{6}$ in THF, $5 \mathrm{mM}$ analyte concentration, $200 \mathrm{mV} / \mathrm{s}$ scan rate). The grey trace represents the solvent blank, the red trace is the initial scan, and the blue trace is the return scan immediately following the first. 
${ }^{1} \mathrm{H}$ NMR $\left(400 \mathrm{MHz}, \mathrm{CDCl}_{3}\right) \delta 10.59,7.78,5.94,4.48,3.54,1.75,0.96$.

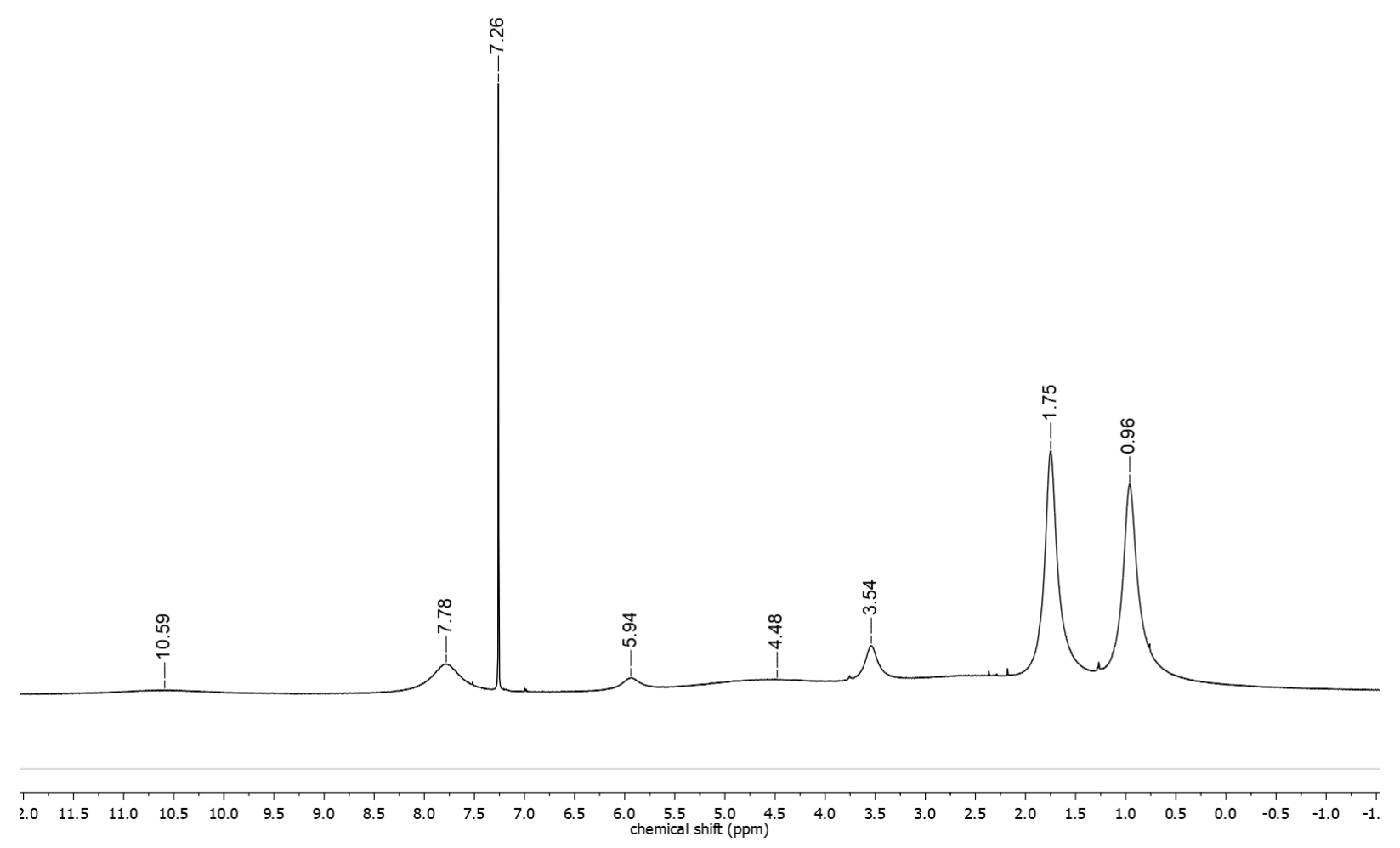

Figure S16: ${ }^{1} \mathrm{H}$ NMR spectrum of 4 in $\mathrm{CDCl}_{3}$. 


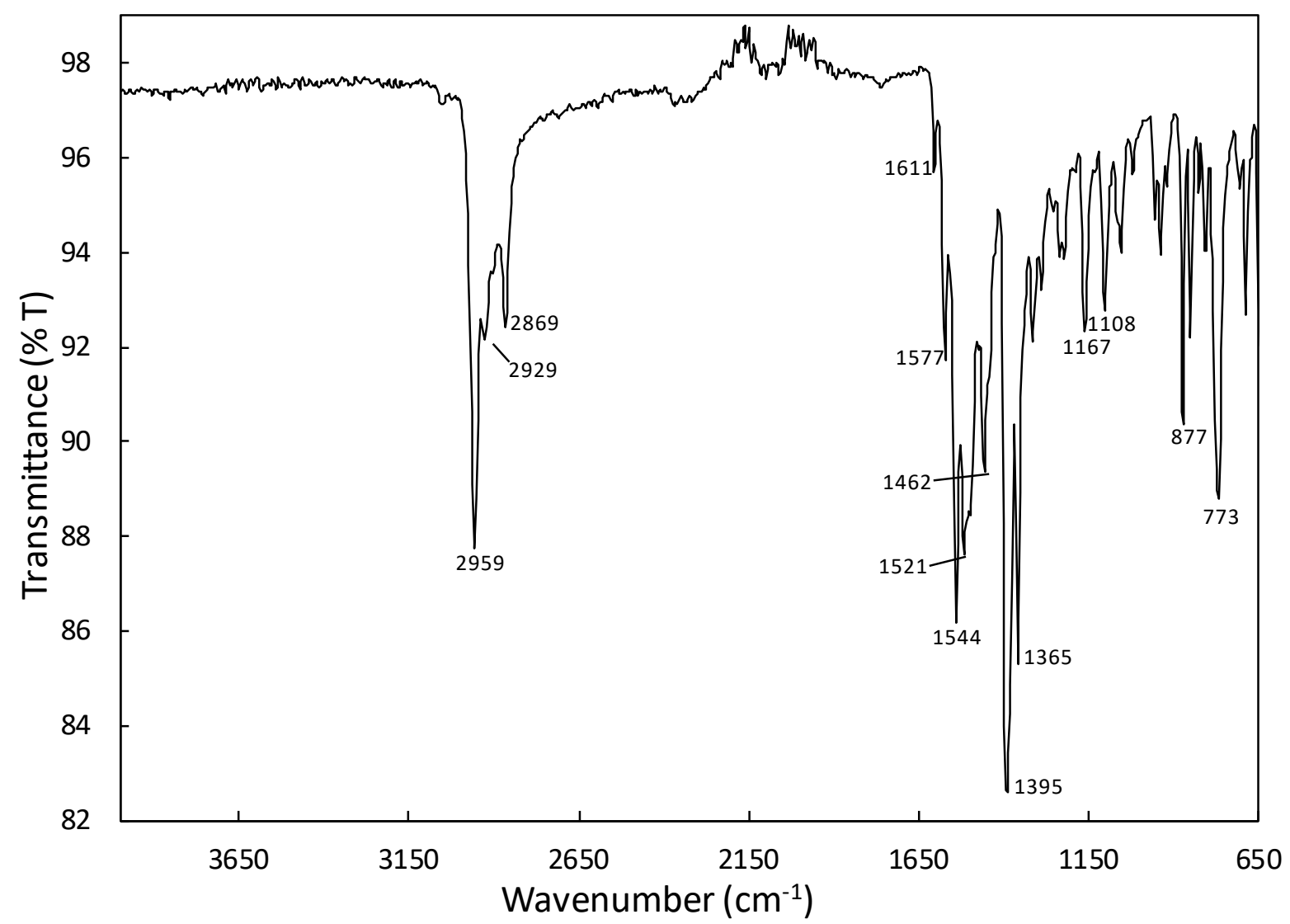

Figure S17: IR spectrum of $\mathbf{4}$ as a neat solid. 


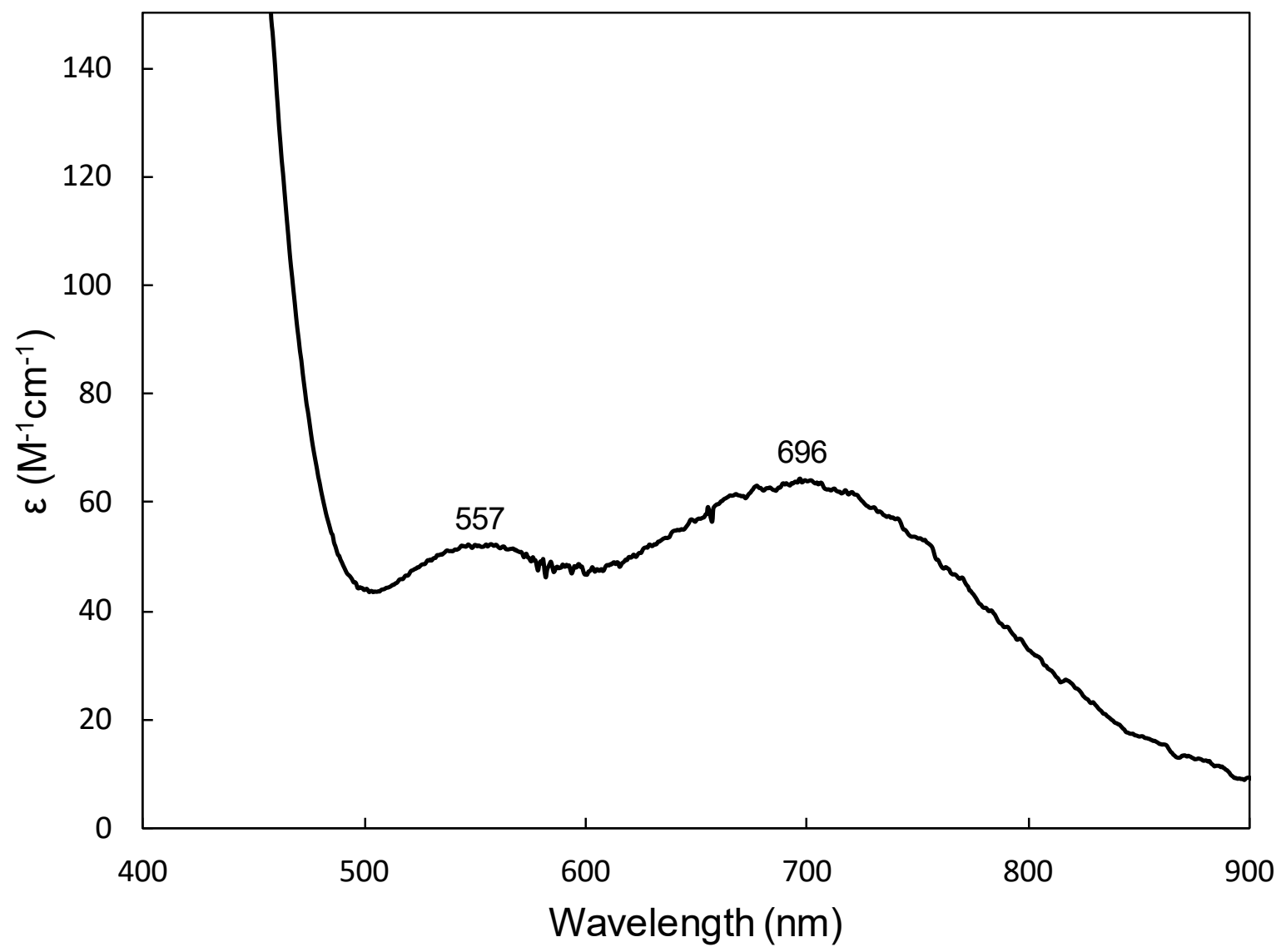

Figure S18: UV-Vis spectrum of 4 in dichloromethane. 


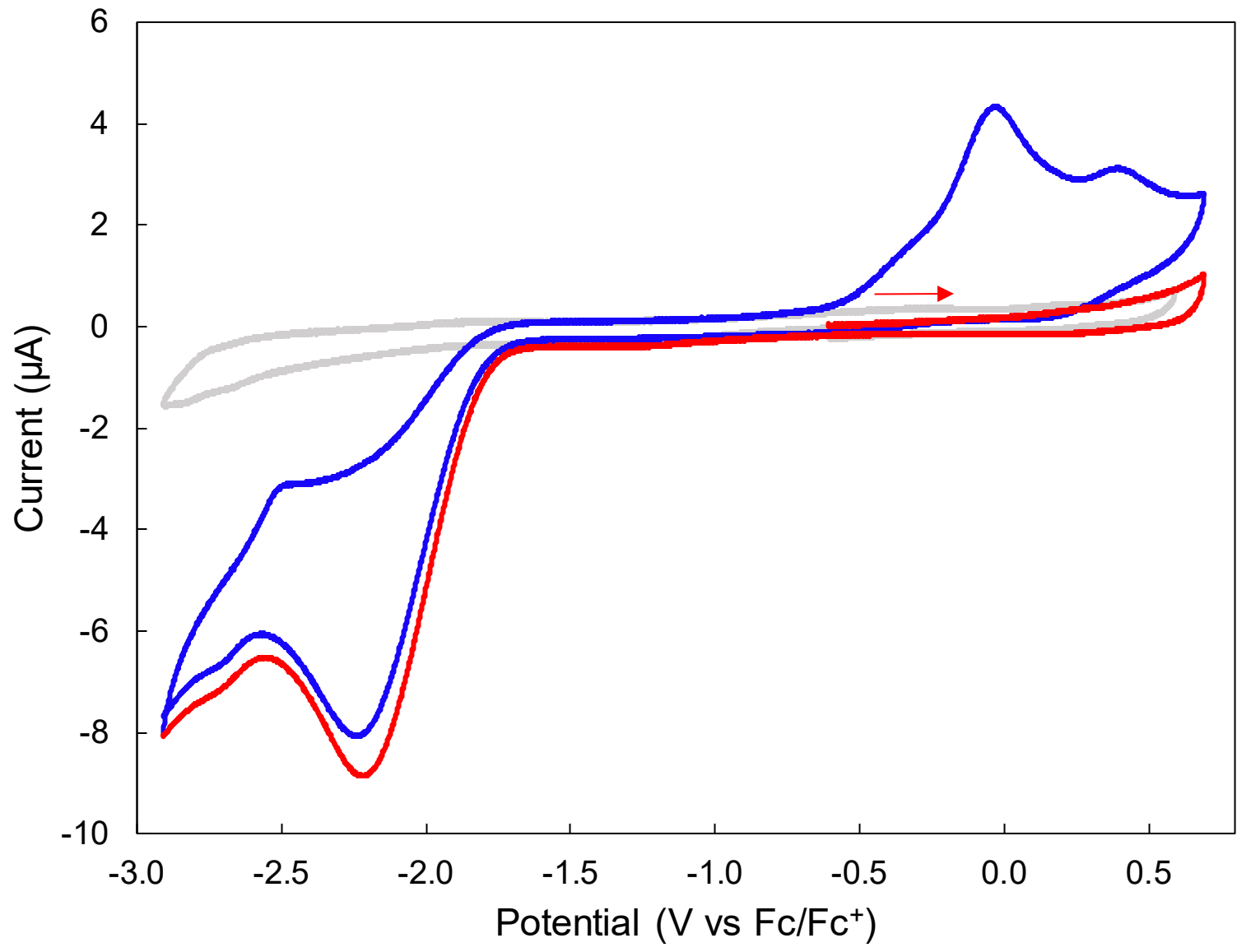

Figure S19: Cyclic voltammogram of 4 (0.1 M TBAPF 6 in THF, $5 \mathrm{mM}$ analyte concentration, $200 \mathrm{mV} / \mathrm{s}$ scan rate). The grey trace represents the solvent blank, the red trace is the initial scan, and the blue trace is the return scan immediately following the first. 
${ }^{1} \mathrm{H}$ NMR $\left(400 \mathrm{MHz}, \mathrm{CDCl}_{3}\right) \delta 10.19,7.65,7.26,6.21,3.79,3.77,3.76,2.92,2.02,1.88,1.88,1.87$, 1.27.

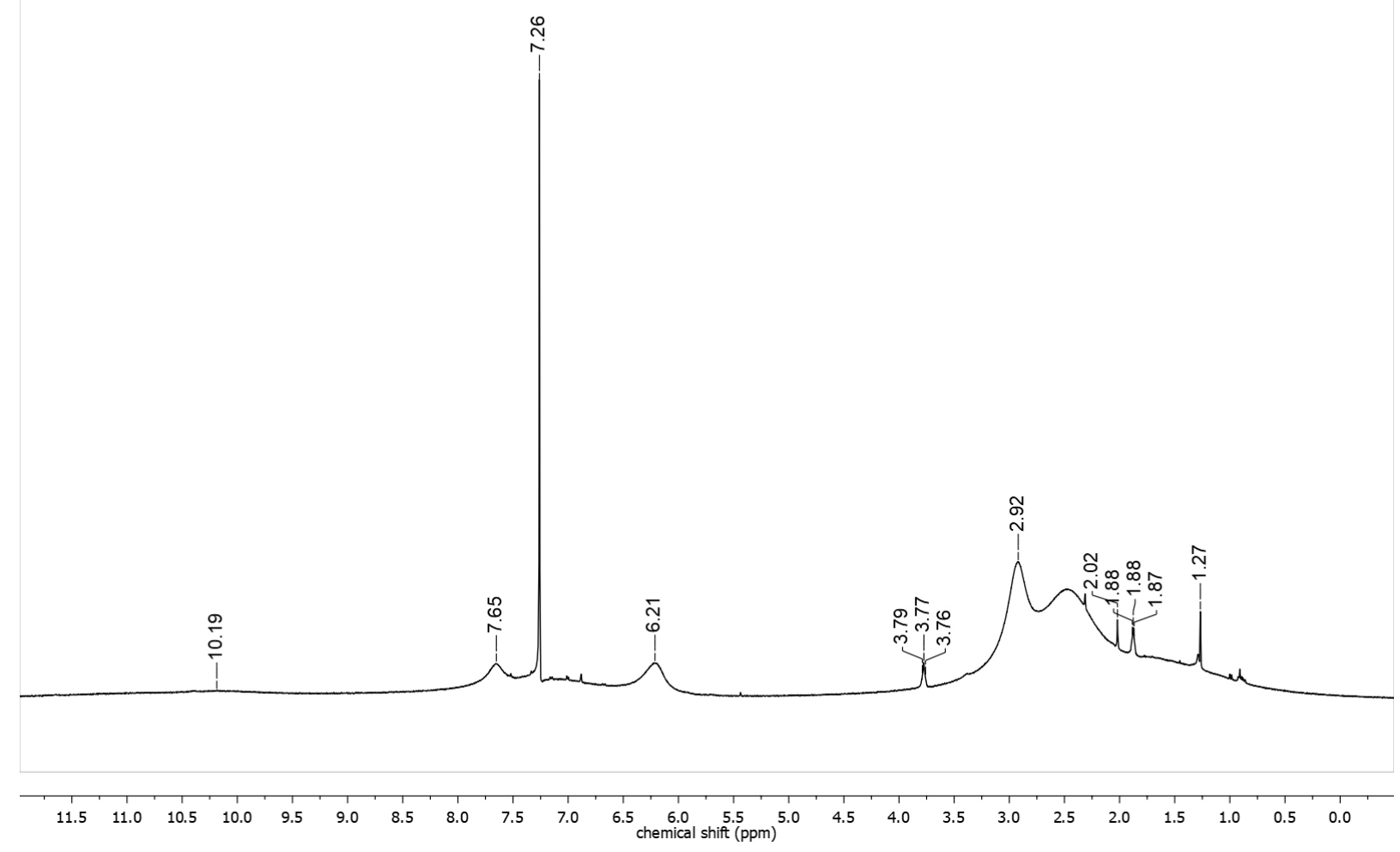

Figure S20: ${ }^{1} \mathrm{H}$ NMR spectrum of 5 in $\mathrm{CDCl}_{3}$. 


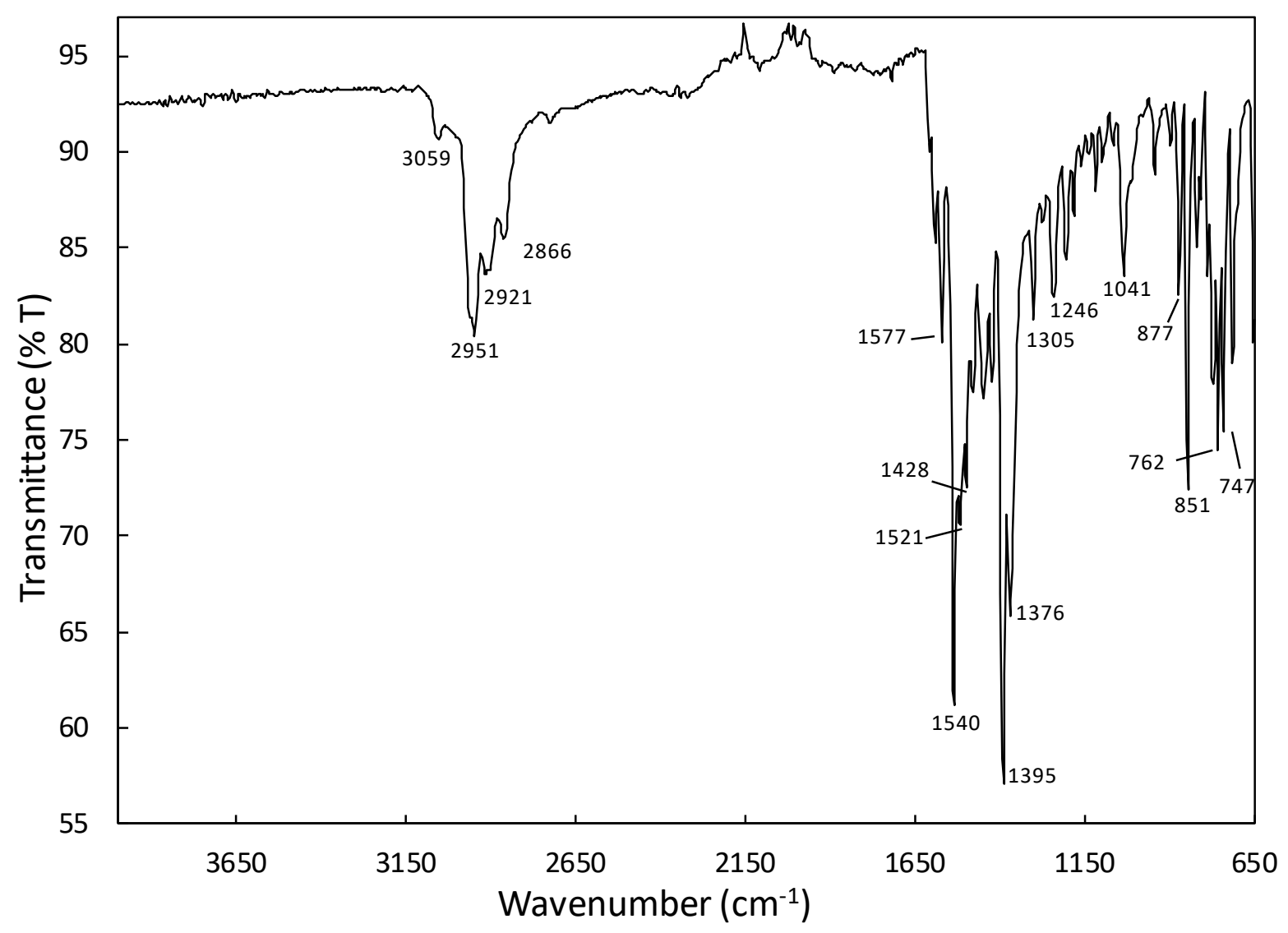

Figure S21: IR spectrum of $\mathbf{5}$ as a neat solid. 


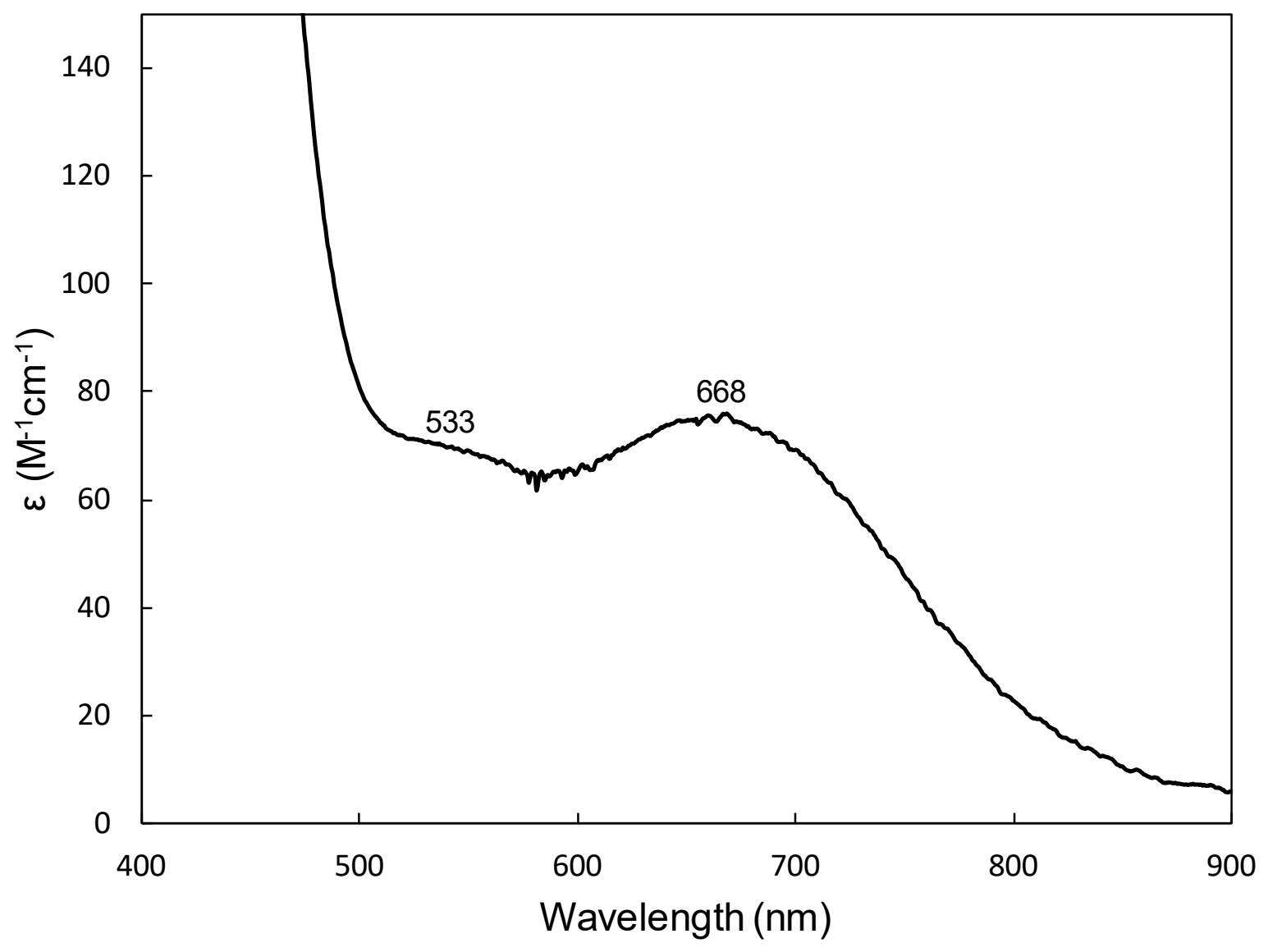

Figure S22: UV-Vis spectrum of $\mathbf{5}$ in dichloromethane. 


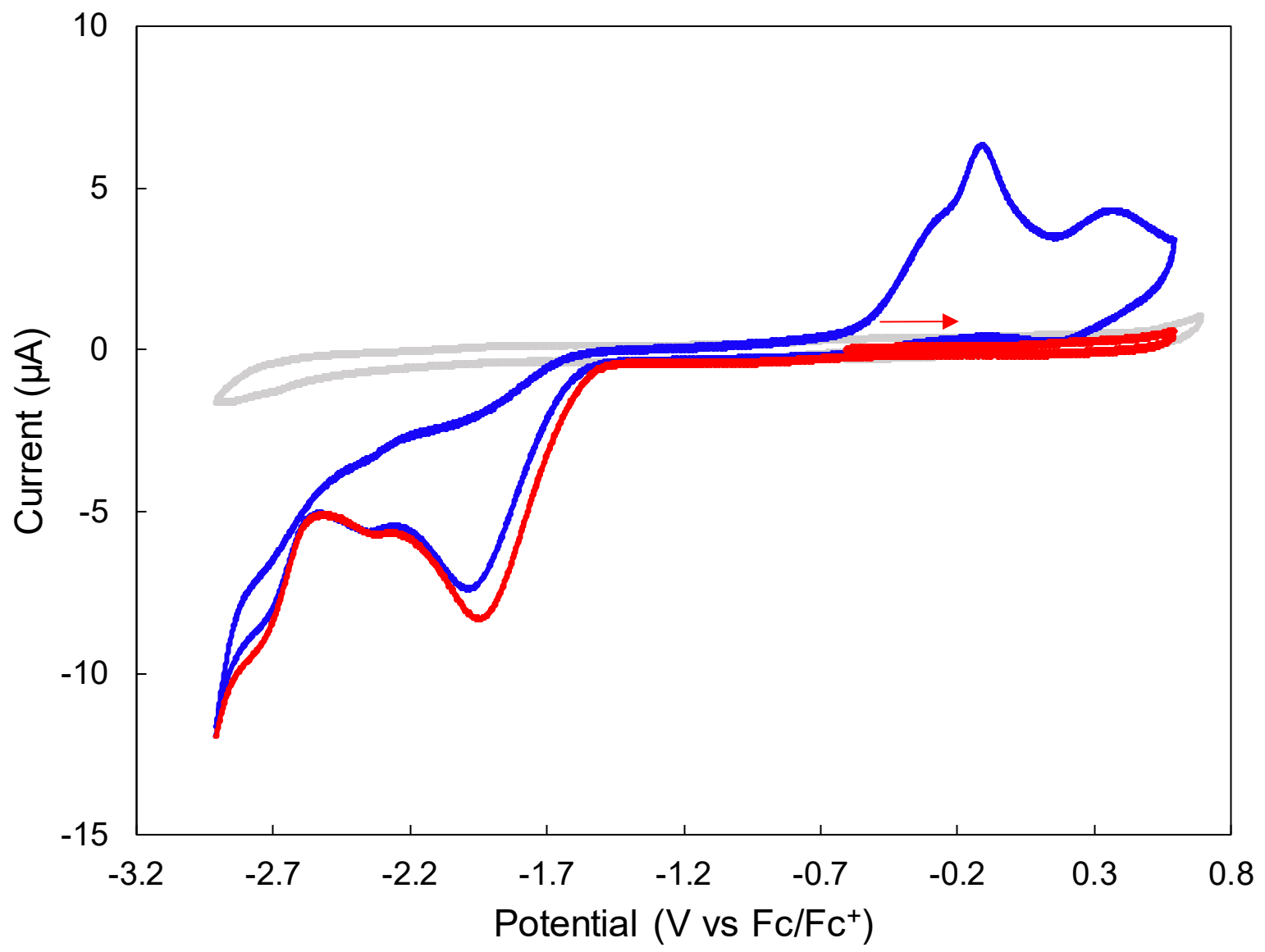

Figure S23: Cyclic voltammogram of 5 (0.1 $\mathrm{M} \mathrm{TBAPF}_{6}$ in THF, $5 \mathrm{mM}$ analyte concentration, $200 \mathrm{mV} / \mathrm{s}$ scan rate). The grey trace represents the solvent blank, the red trace is the initial scan, and the blue trace is the return scan immediately following the first. 
${ }^{1} \mathrm{H}$ NMR $\left(400 \mathrm{MHz}, \mathrm{CDCl}_{3}\right) \delta 8.73,7.35,6.59,6.38,6.14,3.45,2.36,1.92,0.87,0.07$.

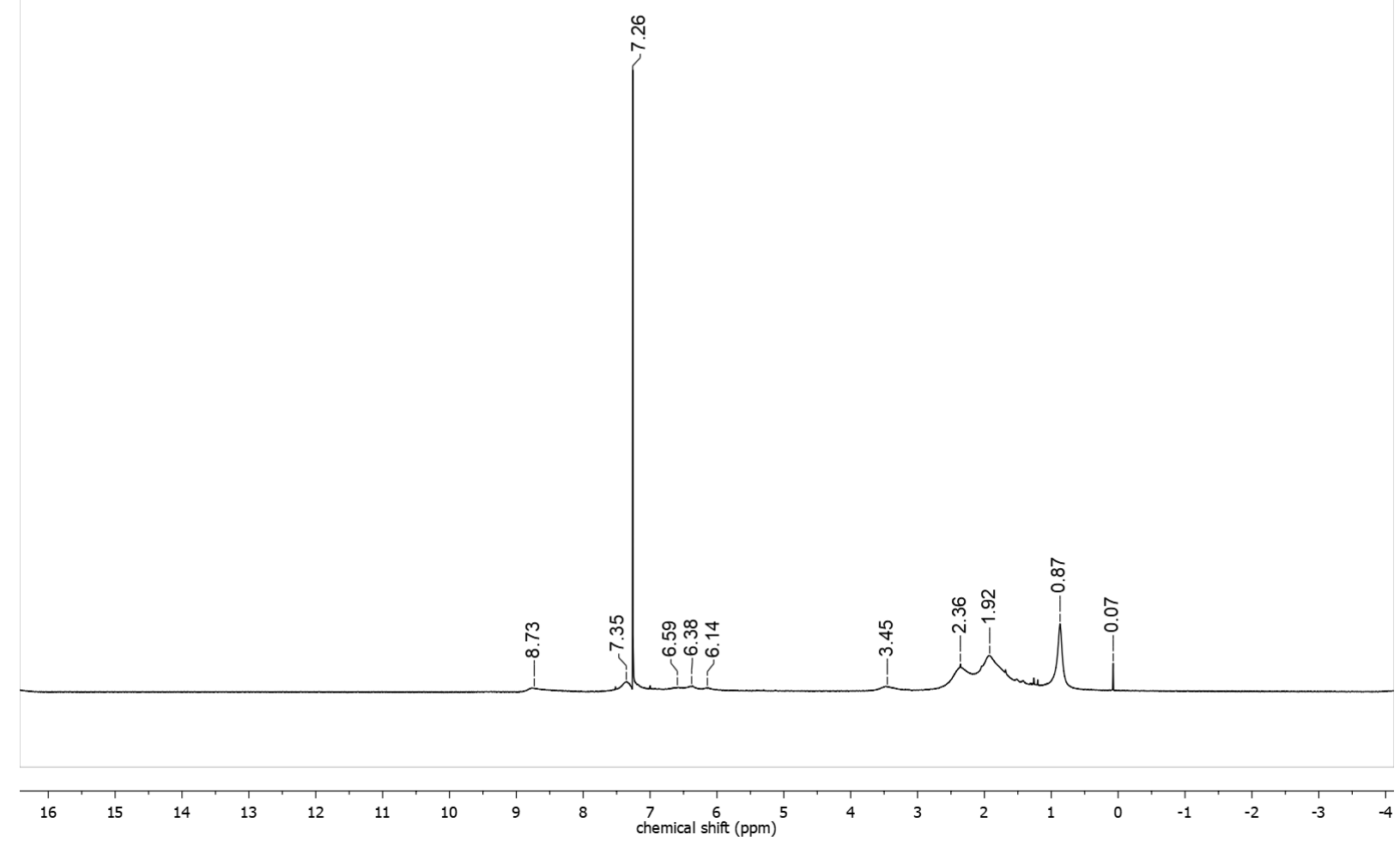

Figure S24: ${ }^{1} \mathrm{H}$ NMR spectrum of 6 in $\mathrm{CDCl}_{3}$. 


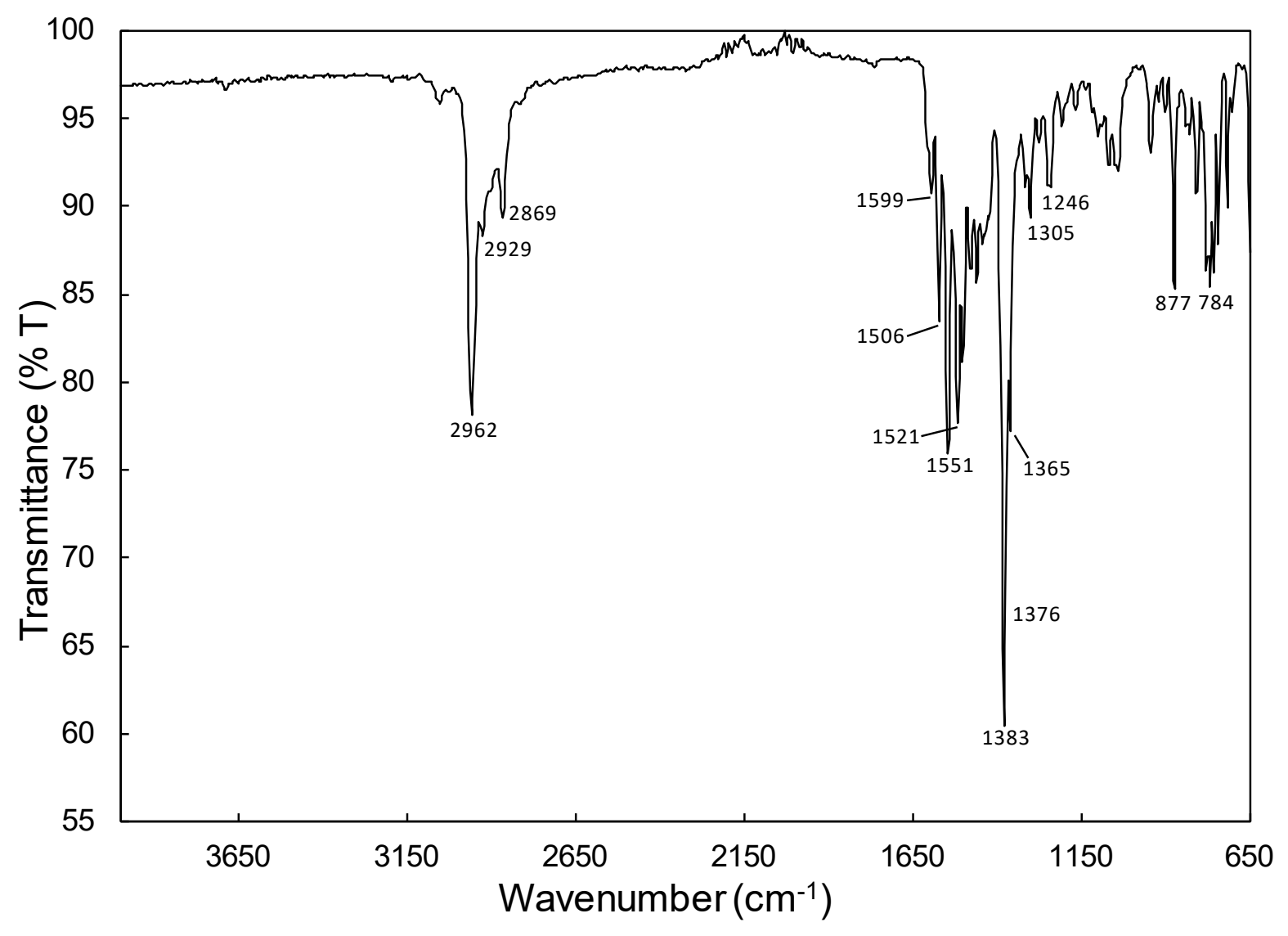

Figure S25: IR Spectrum of $\mathbf{6}$ as a neat solid. 


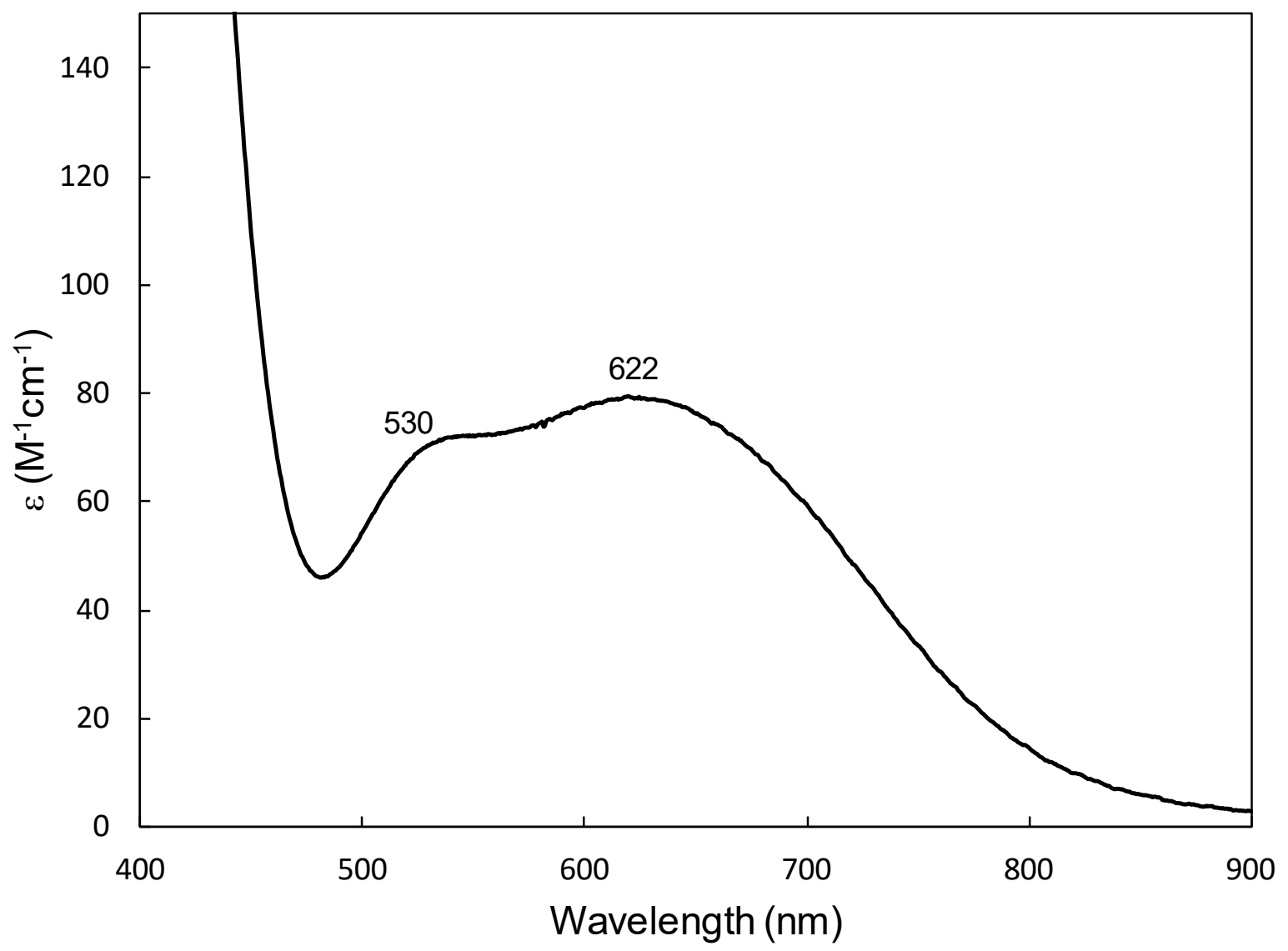

Figure S26: UV-Vis spectrum of 6 in dichloromethane. 


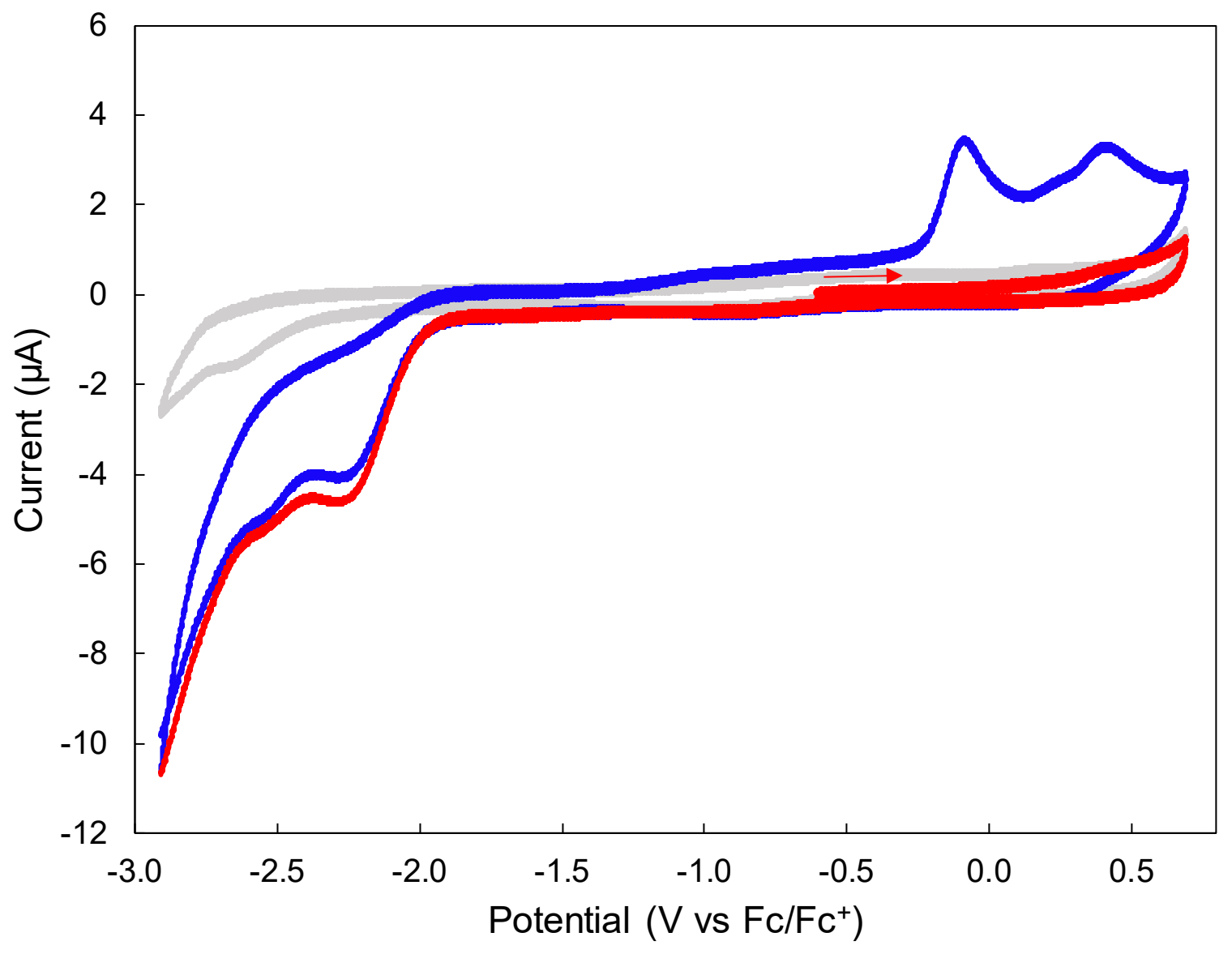

Figure S27: Cyclic voltammogram of 6 (0.1 M TBAPF 6 in THF, $5 \mathrm{mM}$ analyte concentration, $200 \mathrm{mV} / \mathrm{s}$ scan rate). The grey trace represents the solvent blank, the red trace is the initial scan, and the blue trace is the return scan immediately following the first. 


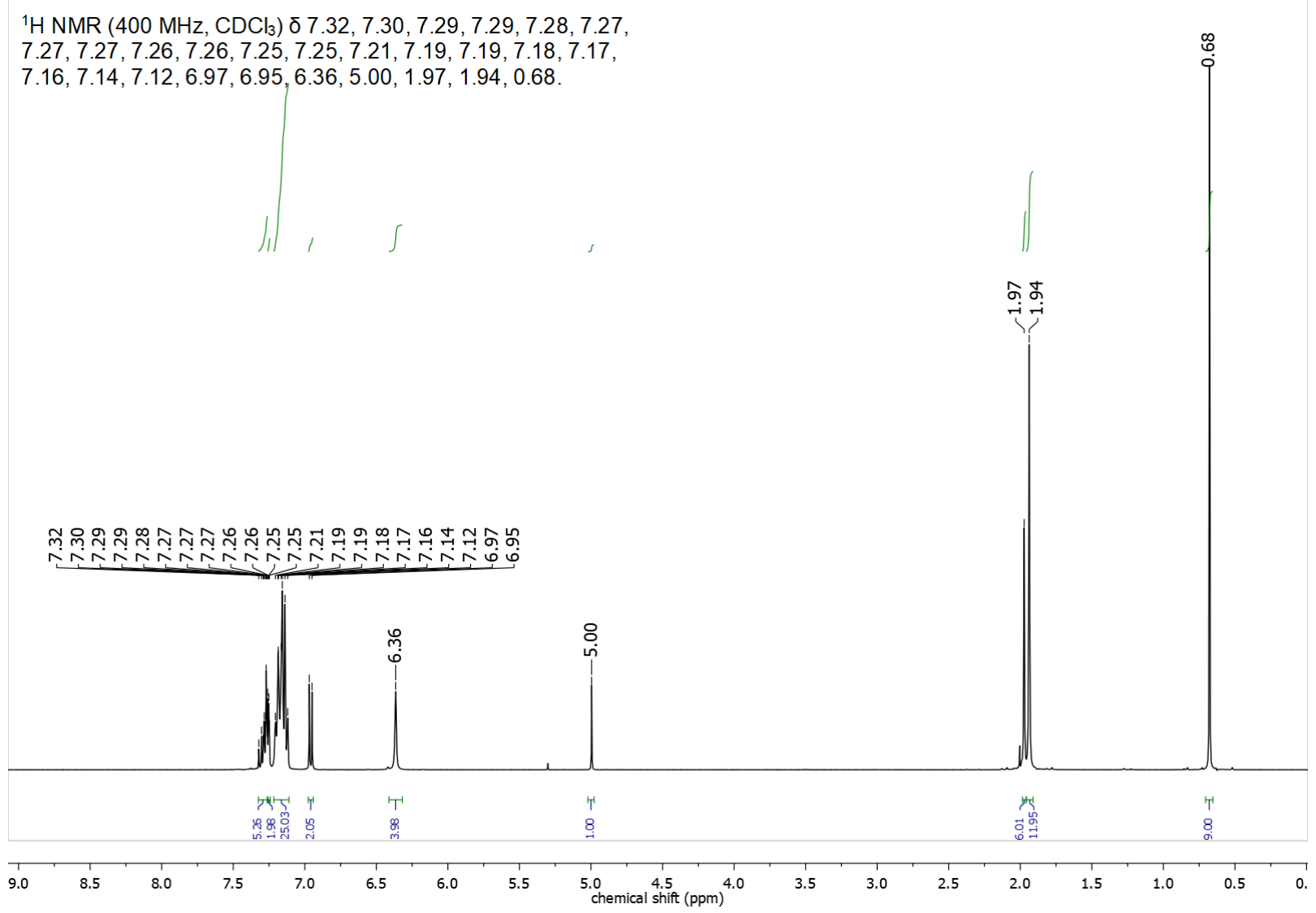

Figure S28: ${ }^{1} \mathrm{H}$ NMR of 7 in $\mathrm{CDCl}_{3}$. 
${ }^{13} \mathrm{C}$ NMR $\left(101 \mathrm{MHz}, \mathrm{CDCl}_{3}\right) \delta 197.49,186.23,143.48,139.23$,

$139.00,135.91,134.94,134.69,134.46,134.06,133.90$

$128.87,128.50,128.15,128.07,127.70,127.09,95.12,77.34$

$77.02,76.70,40.45,27.81,20.89,20.86$.

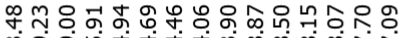

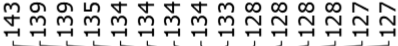

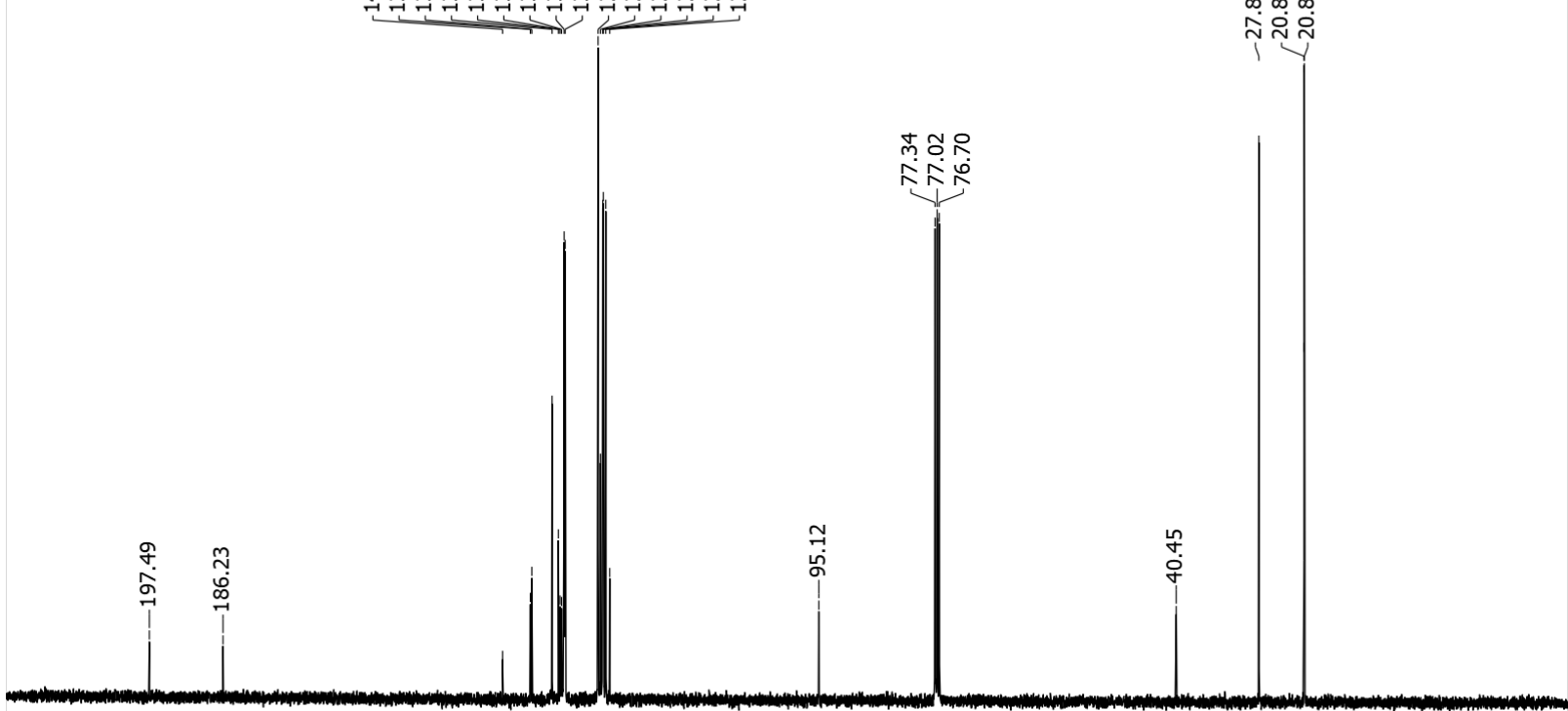

$\begin{array}{llllllllllll}210 & 200 & 190 & 180 & 170 & 160 & 150 & 140 & 130 & 120 & \begin{array}{l}110 \\ \text { chemical shift (ppm) }\end{array}\end{array}$

Figure S29: ${ }^{13} \mathrm{C}$ NMR spectrum of 7 in $\mathrm{CDCl}_{3}$. 
${ }^{31} \mathrm{P}$ NMR $\left(162 \mathrm{MHz}, \mathrm{CDCl}_{3}\right) \delta-5.60$.

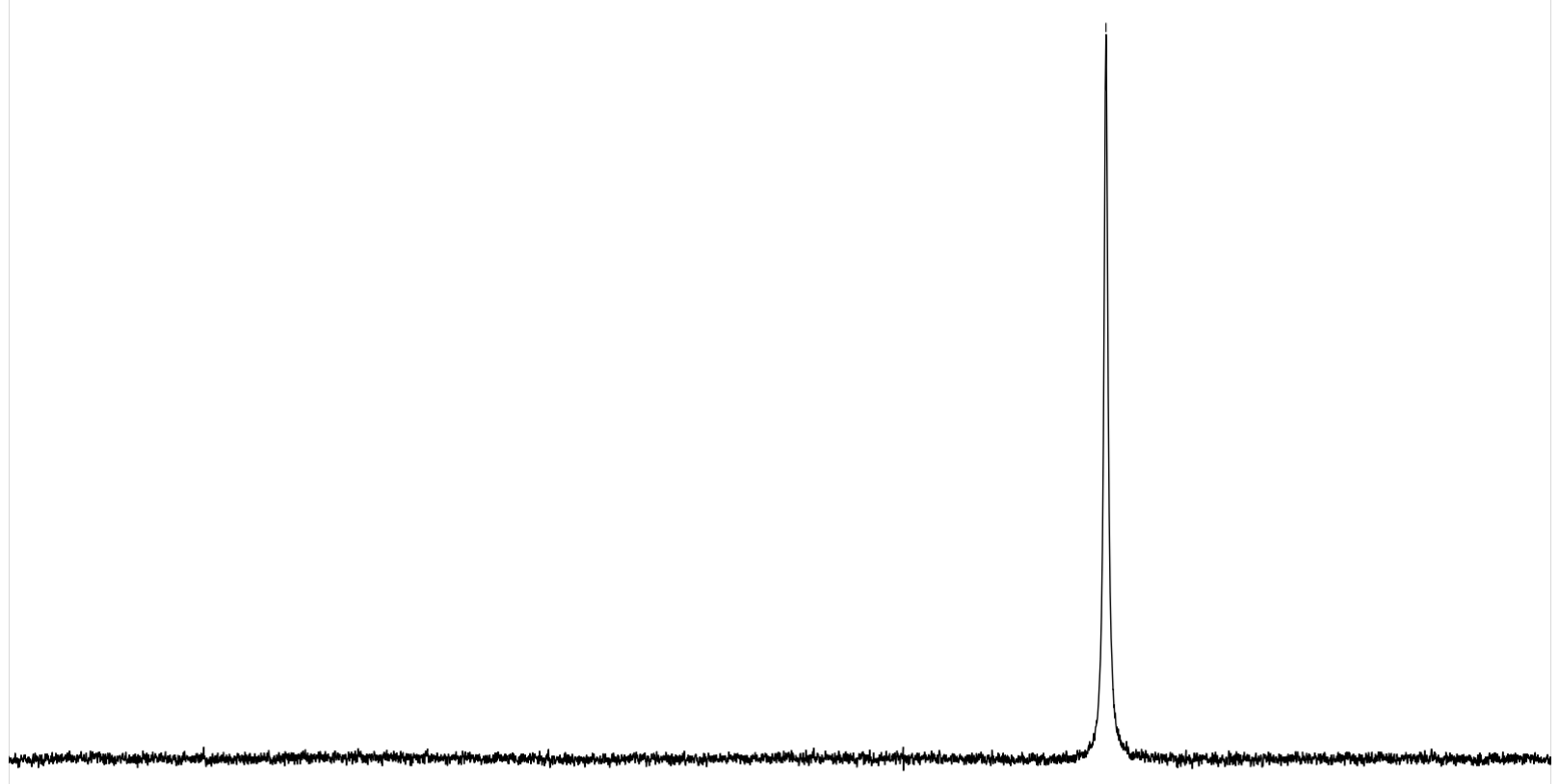

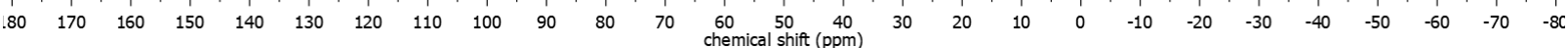

Figure S30: ${ }^{31} \mathrm{P}$ NMR of 7 in $\mathrm{CDCl}_{3}$. 


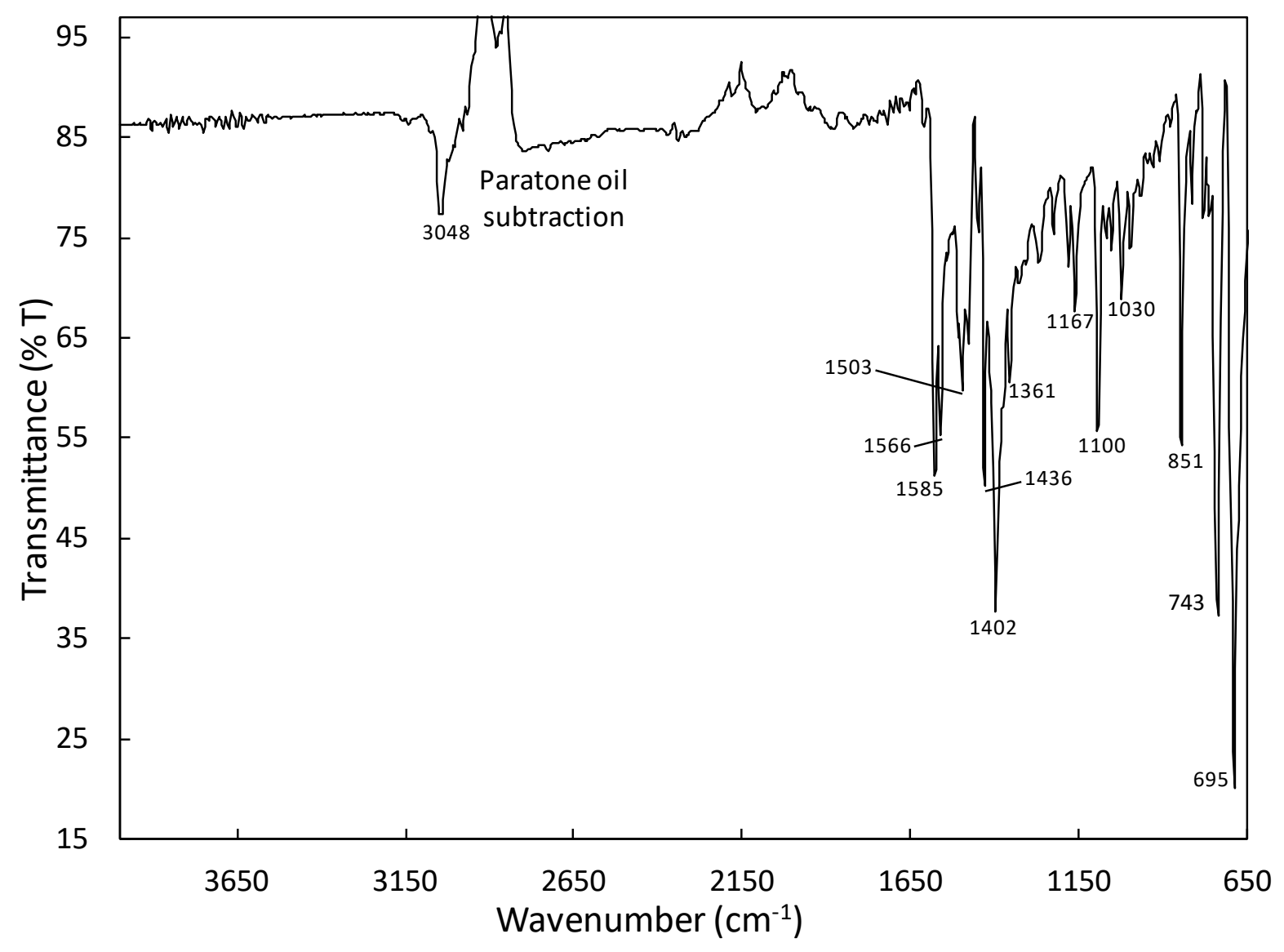

Figure S31: IR spectrum of 7 dispersed in paratone oil. 


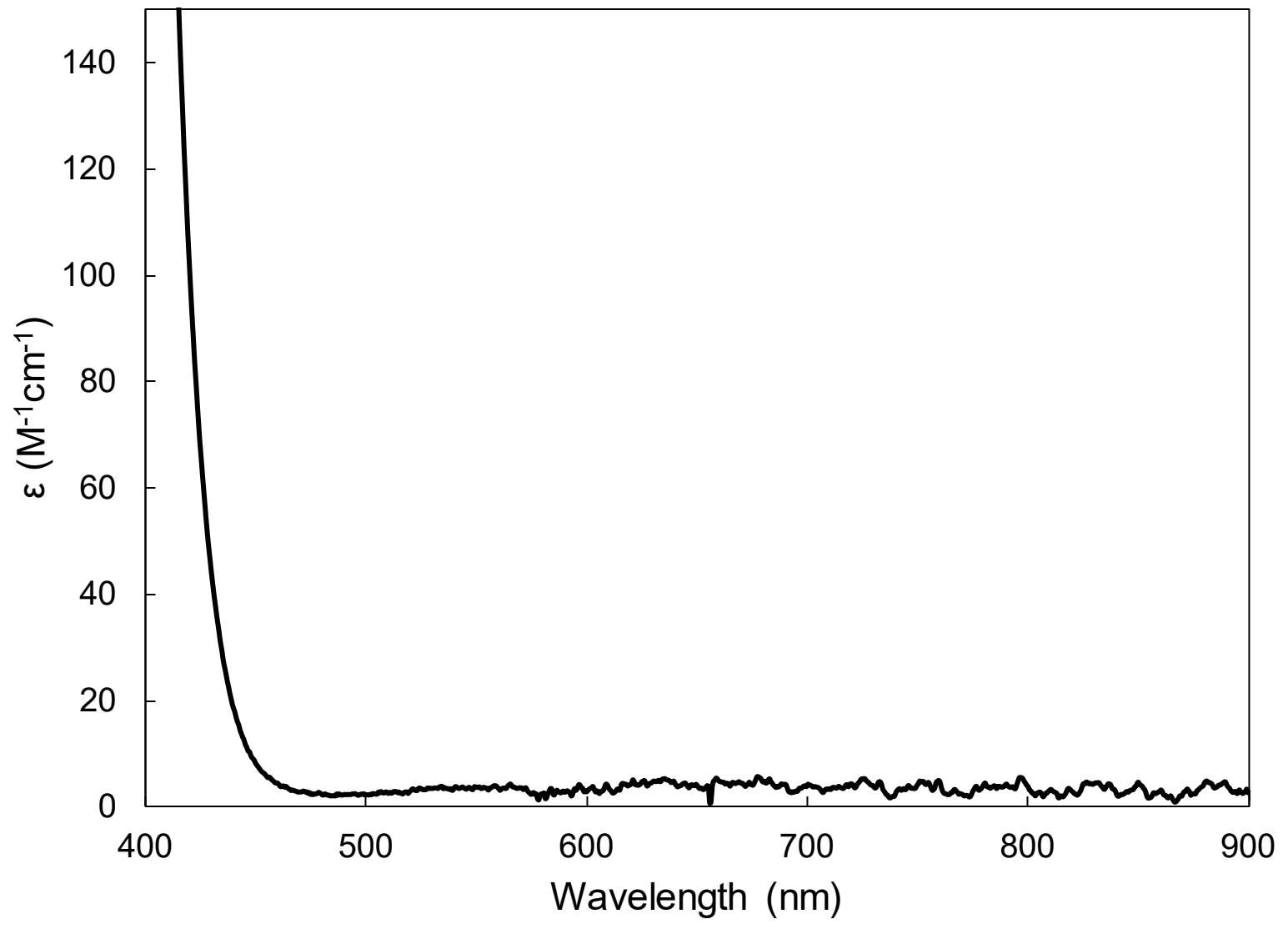

Figure S32: UV-Vis spectrum of 7 in dichloromethane. 
Table S33: Results of the initial catalytic screen using $\mathbf{2}$ as a catalyst.

\begin{tabular}{ccccccc}
\hline $\begin{array}{c}\text { Temperature } \\
\left({ }^{\circ} \mathrm{C}\right)\end{array}$ & $\begin{array}{c}\text { Time } \\
(\text { days })\end{array}$ & $\begin{array}{c}\text { Solvent } \\
\text { volume } \\
(\mathrm{mL})\end{array}$ & $\begin{array}{c}\text { Catalyst } \\
\text { loading } \\
(\mathrm{mmol})\end{array}$ & $\begin{array}{c}2- \\
\text { Napthol } \\
\text { amount } \\
(\mathrm{mmol})\end{array}$ & $\begin{array}{c}\text { Bromobenzene } \\
\text { amount }(\mathrm{mmol})\end{array}$ & $\begin{array}{c}\% \\
\text { Conversion }\end{array}$ \\
\hline 90 & 6 & 5 & 0.1 & 4 & 2 & 0.06 \\
90 & 6 & 5 & 0.2 & 2 & 2 & 0.18 \\
90 & 6 & 5 & 0.4 & 2 & 2 & 0.19 \\
90 & 6 & 5 & 0.05 & 2 & 2 & 0.10 \\
90 & 6 & 5 & 0.02 & 2 & 2 & 0.05 \\
90 & 6 & 5 & 0.01 & 2 & 2 & 0.03 \\
90 & 1 & 5 & 1 & 2 & 2 & 0.06 \\
90 & 2 & 5 & 0.1 & 2 & 2 & 0.05 \\
90 & 3 & 5 & 0.1 & 2 & 2 & 0.05 \\
90 & 4 & 5 & 0.1 & 2 & 2 & 0.07 \\
90 & 5 & 5 & 0.1 & 2 & 2 & 0.07 \\
90 & 6 & 5 & 0.1 & 1 & 2 & 0.31 \\
90 & 6 & 1 & 0.1 & 1 & 1 & 0.25 \\
90 & 6 & 5 & 0.1 & 1 & 1 & 0.26 \\
\hline
\end{tabular}




\section{Results of general catalytic screen}

Table S34: Results of the general catalytic screens using fixed conditions while varying the catalyst.

\begin{tabular}{|c|c|c|c|c|c|c|c|}
\hline 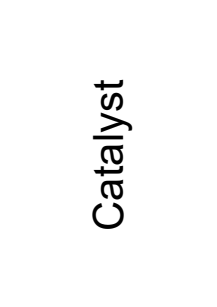 & 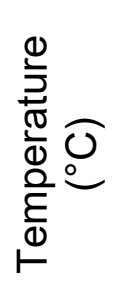 & $\begin{array}{l}\frac{\pi}{d} \\
\stackrel{0}{0} \\
\stackrel{0}{E} \\
i=\end{array}$ & 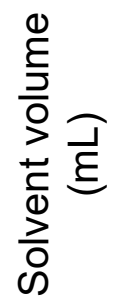 & 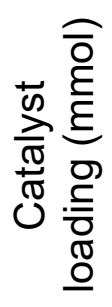 & 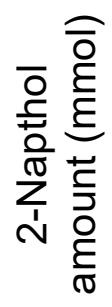 & 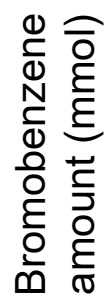 & $\begin{array}{l}\frac{c}{0} \\
\frac{0}{0} \\
\searrow \\
\searrow \\
0 \\
0 \\
0\end{array}$ \\
\hline $\mathrm{Cu}(\mathrm{acac})_{2}$ & 90 & 1 & 5 & 0.1 & 1 & 2 & 0.21 \\
\hline $\mathrm{Cu}(\mathrm{dpm})_{2}$ & 90 & 1 & 5 & 0.1 & 1 & 2 & 0.13 \\
\hline $\mathrm{Cu}(\mathrm{dbm})_{2}$ & 90 & 1 & 5 & 0.1 & 1 & 2 & 0.18 \\
\hline $\mathrm{Cu}(\mathrm{bzac})_{2}$ & 90 & 1 & 5 & 0.1 & 1 & 2 & 0.28 \\
\hline 2 & 90 & 1 & 5 & 0.1 & 1 & 2 & 0.12 \\
\hline 3 & 90 & 1 & 5 & 0.1 & 1 & 2 & 0.12 \\
\hline 4 & 90 & 1 & 5 & 0.1 & 1 & 2 & 0.14 \\
\hline 5 & 90 & 1 & 5 & 0.1 & 1 & 2 & 0.15 \\
\hline $\mathrm{CuBr}$ & 90 & 1 & 5 & 0.1 & 1 & 2 & 0 \\
\hline $\mathrm{CuBr} / \mathrm{K}\left(\mathbf{L}^{2}\right)$ & 90 & 1 & 5 & 0.1 & 1 & 2 & 0.03 \\
\hline
\end{tabular}




\section{Cyclic Voltammograms of Parent Copper(II) $\beta$-Diketonate Complexes}

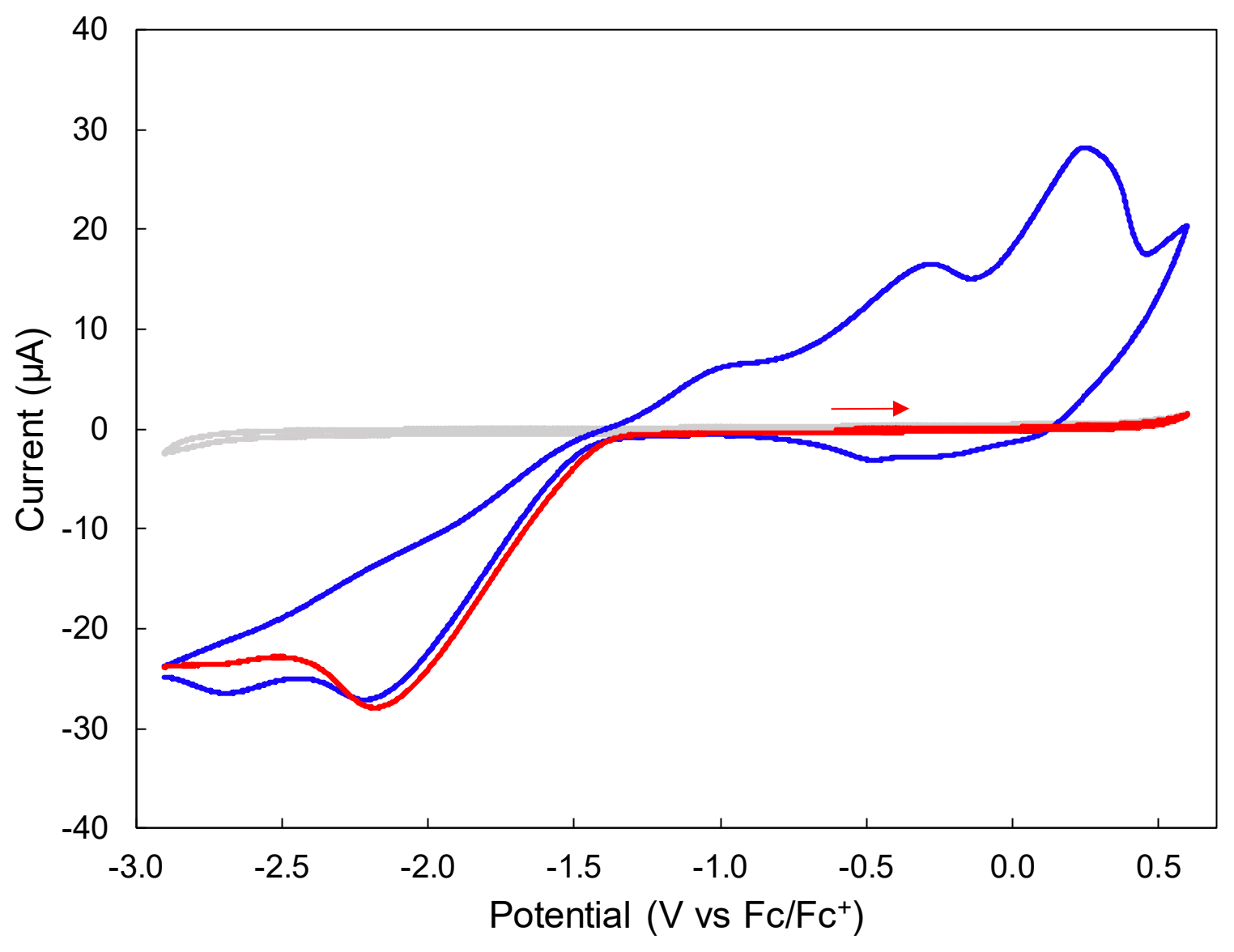

Figure S35: Cyclic voltammogram of $\mathrm{Cu}(\mathrm{acac})_{2}$ (0.1 M TBAPF 6 in THF, $5 \mathrm{mM}$ analyte concentration, $200 \mathrm{mV} / \mathrm{s}$ scan rate). The grey trace represents the solvent blank, the red trace is the initial scan, and the blue trace is the return scan immediately following the first. 


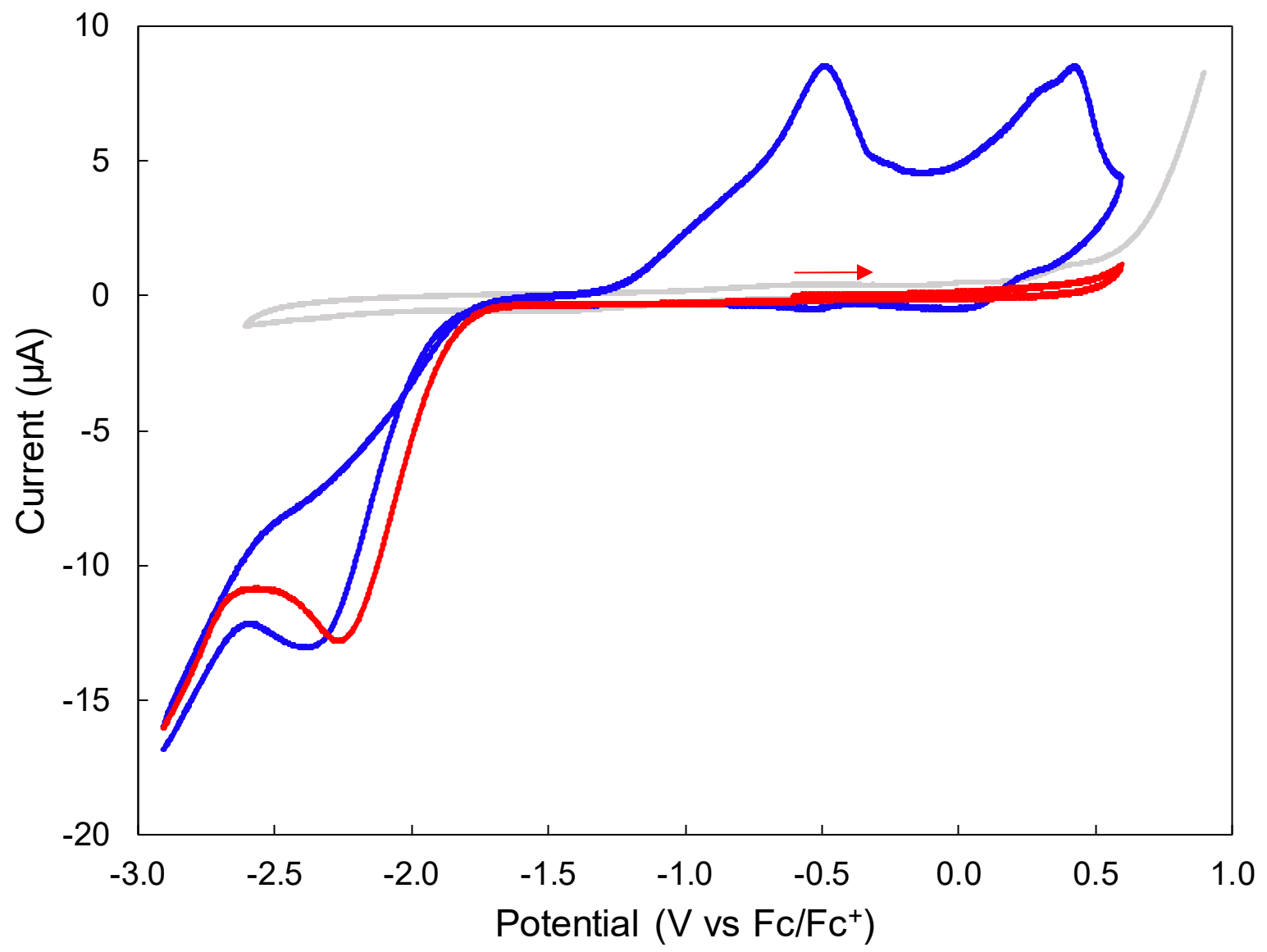

Figure S36: Cyclic voltammogram of $\mathrm{Cu}(\mathrm{dpm})_{2}\left(0.1 \mathrm{M} \mathrm{TBAPF}_{6}\right.$ in THF, $5 \mathrm{mM}$ analyte concentration, $200 \mathrm{mV} / \mathrm{s}$ scan rate). The grey trace represents the solvent blank, the red trace is the initial scan, and the blue trace is the return scan immediately following the first. 


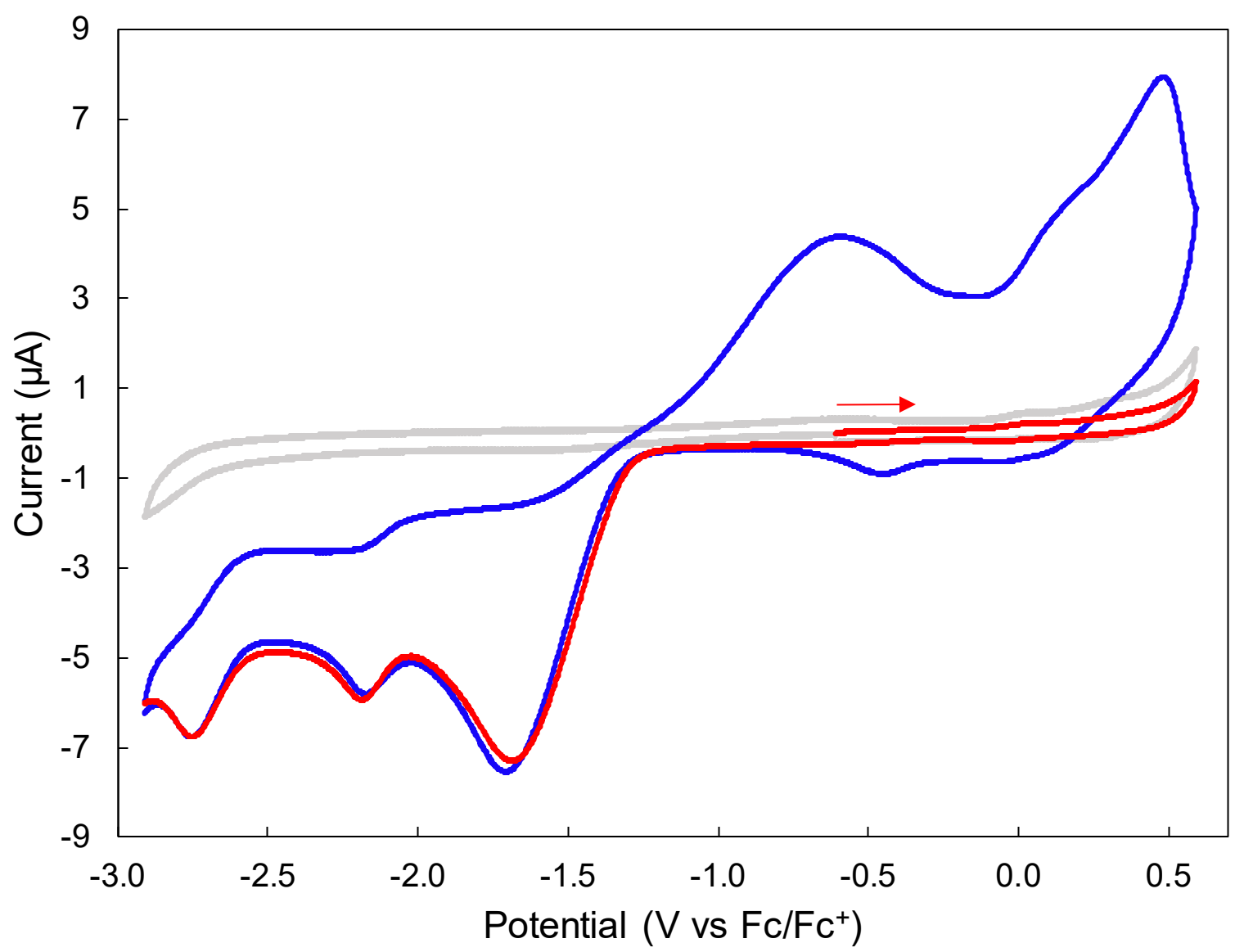

Figure S37: Cyclic voltammogram of $\mathrm{Cu}(\mathrm{dbm})_{2}\left(0.1 \mathrm{M}_{\text {TBAPF }}\right.$ in THF, $5 \mathrm{mM}$ analyte concentration, $200 \mathrm{mV} / \mathrm{s}$ scan rate). The grey trace represents the solvent blank, the red trace is the initial scan, and the blue trace is the return scan immediately following the first. 


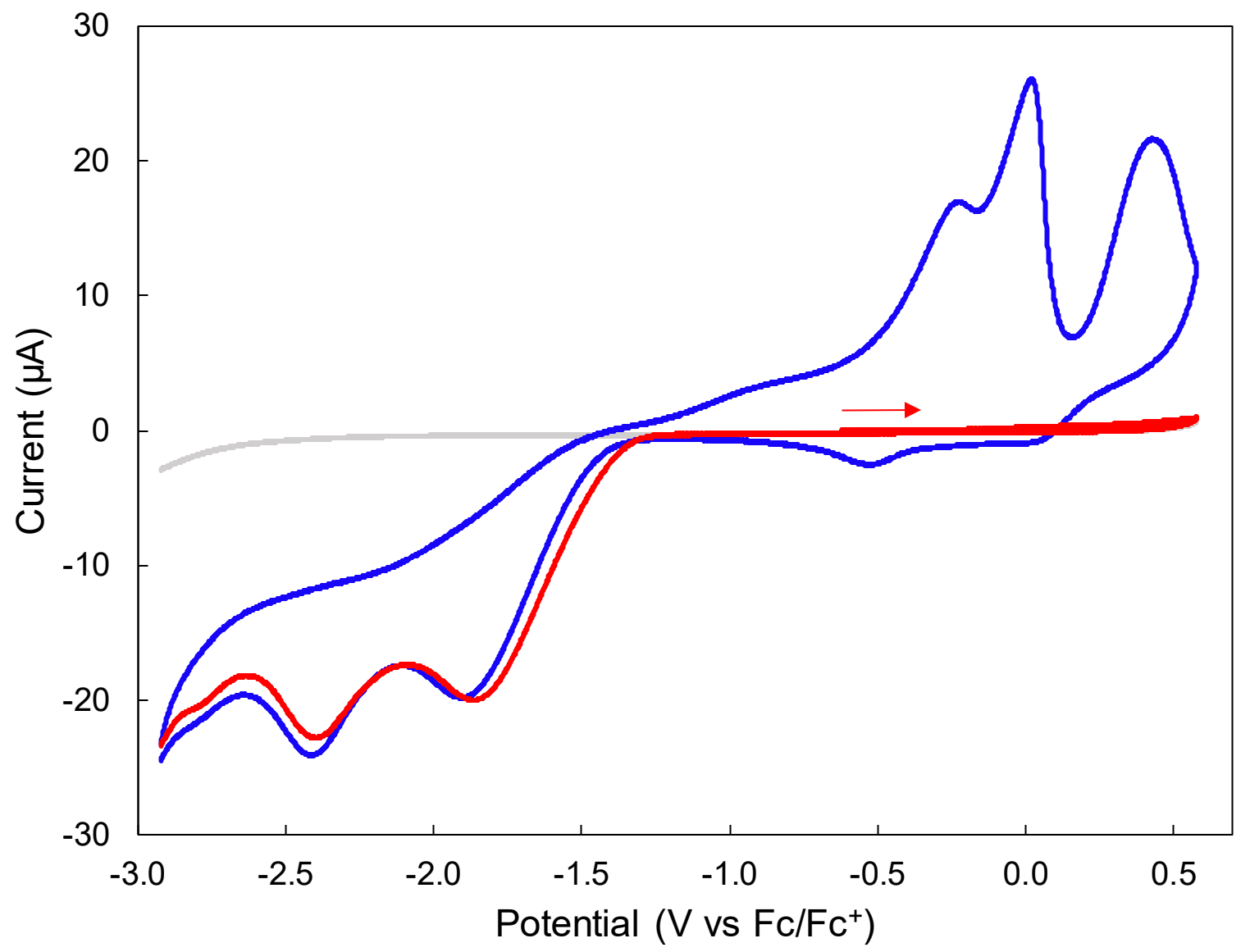

Figure S38: Cyclic voltammogram of $\mathrm{Cu}(\mathrm{bzac})_{2}$ (0.1 M TBAPF 6 in THF, $5 \mathrm{mM}$ analyte concentration, $200 \mathrm{mV} / \mathrm{s}$ scan rate). The grey trace represents the solvent blank, the red trace is the initial scan, and the blue trace is the return scan immediately following the first. 


\section{X-Ray Crystallographic Details}

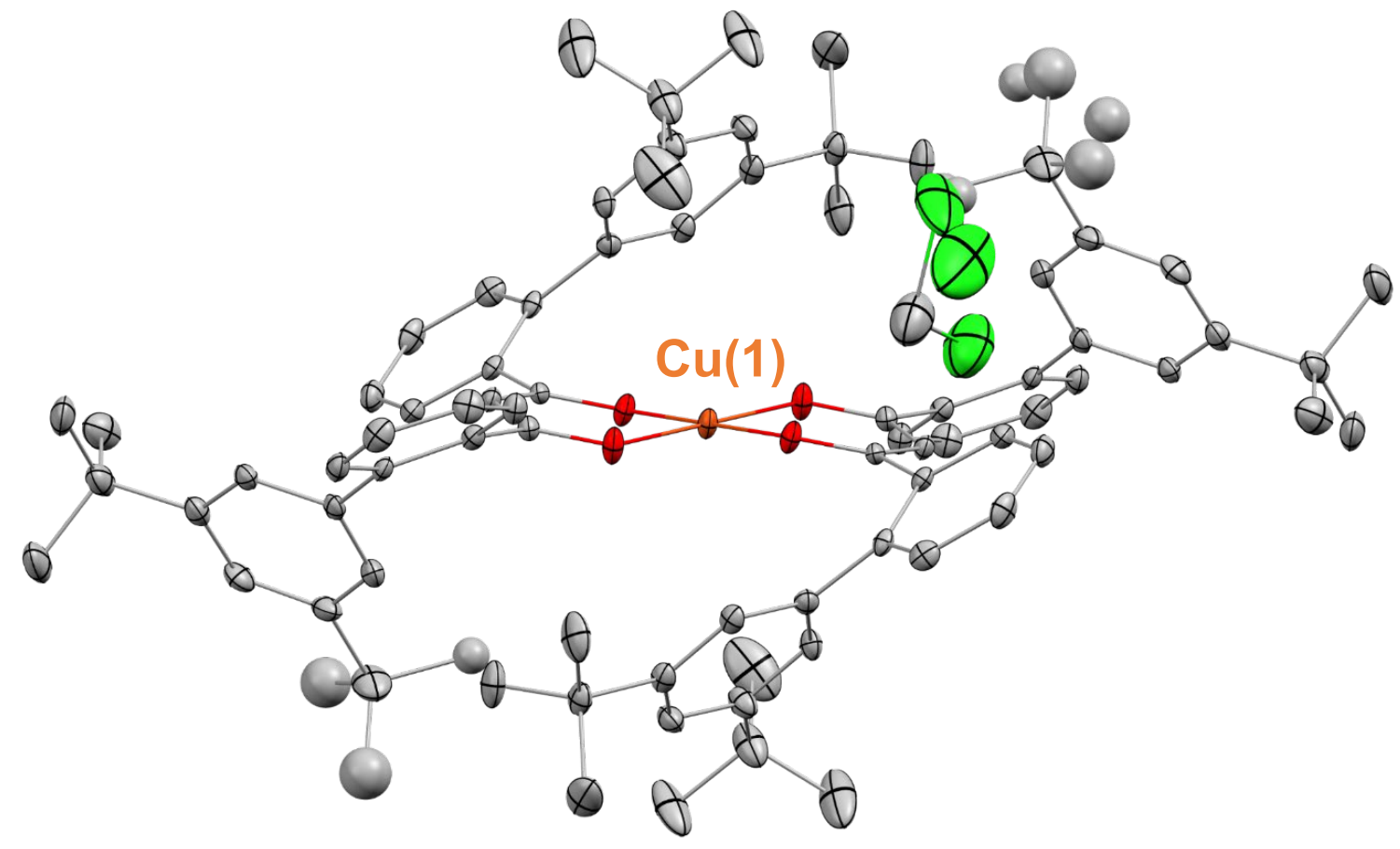

Figure S39: Thermal ellipsoid plot of 1 with ellipsoids drawn at a $50 \%$ confidence level. 


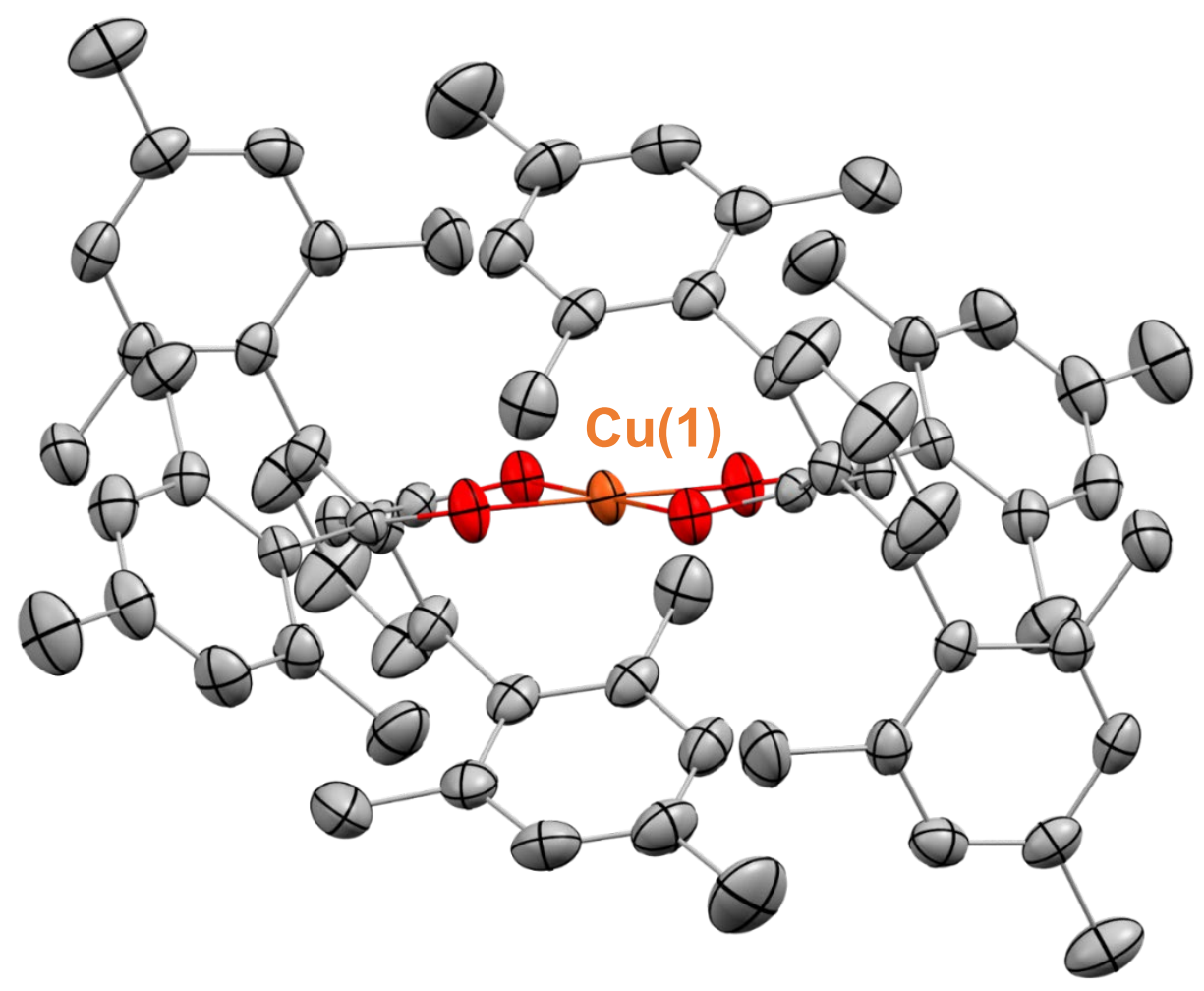

Figure S40: Thermal ellipsoid plot of 3 with ellipsoids drawn at a $50 \%$ confidence level. 


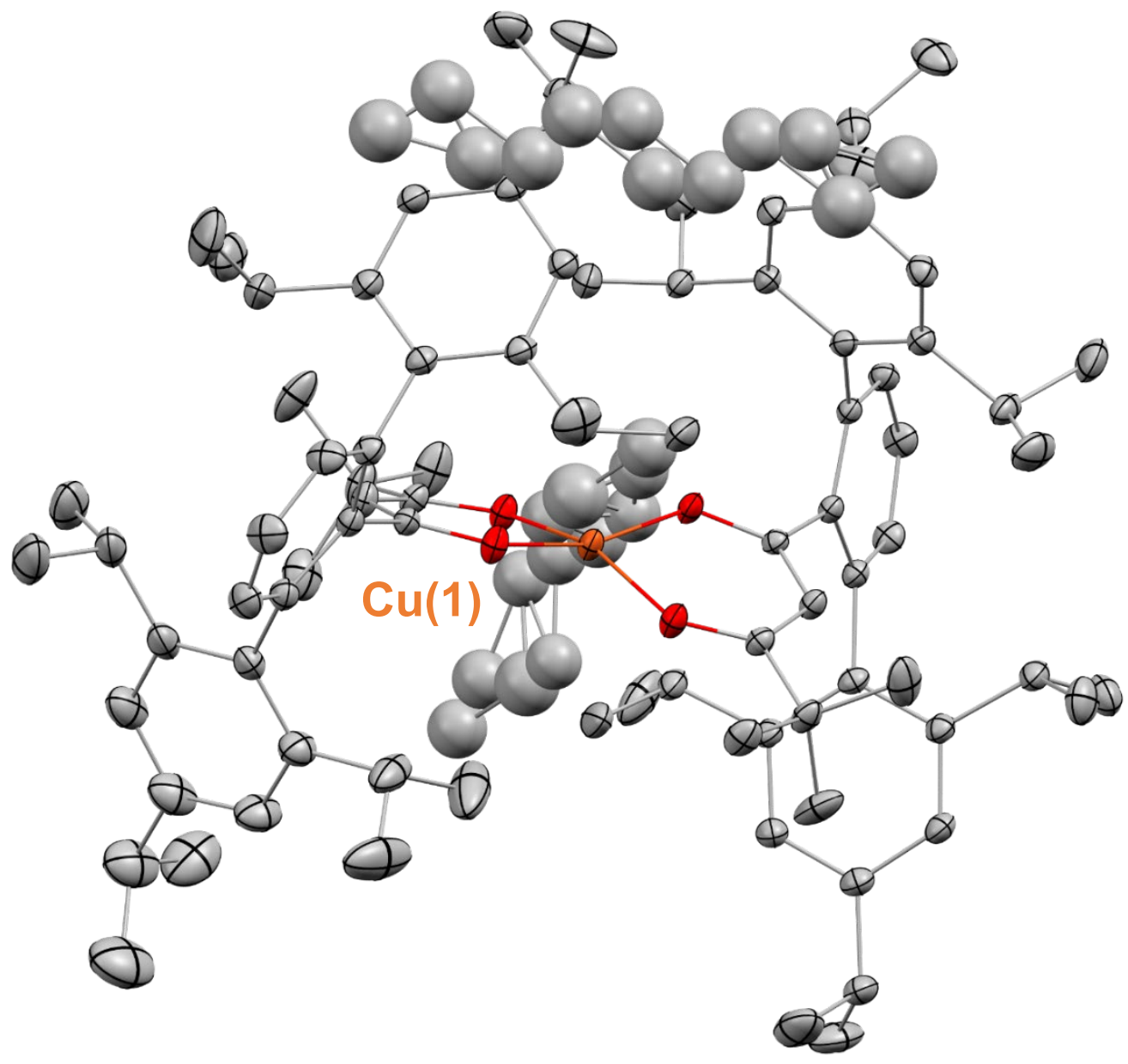

Figure S41: Thermal ellipsoid plot of 4 with ellipsoids drawn at a 50\% confidence level. 


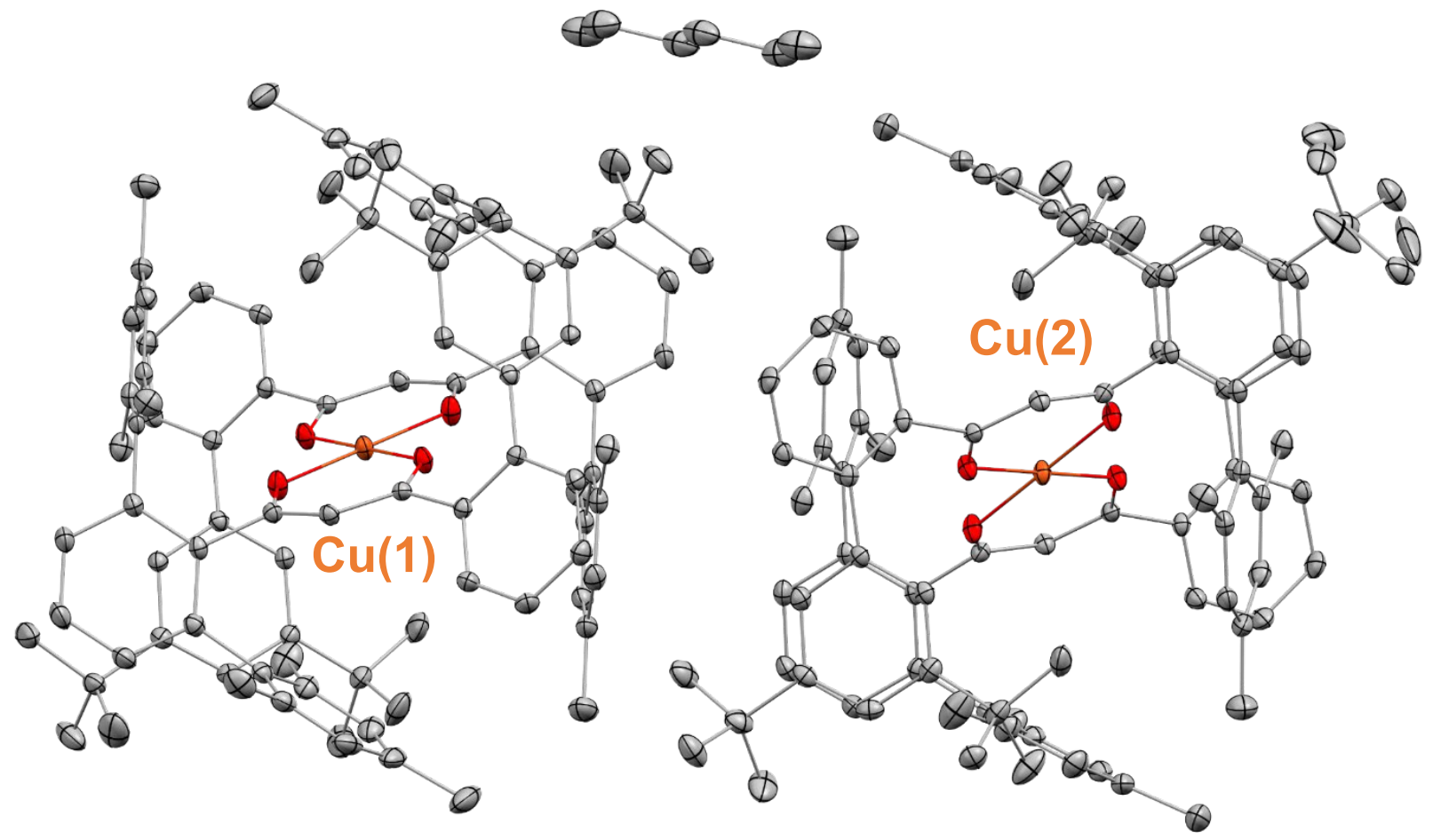

Figure S42: Thermal ellipsoid plot of 5 with ellipsoids drawn at a $50 \%$ confidence level. 


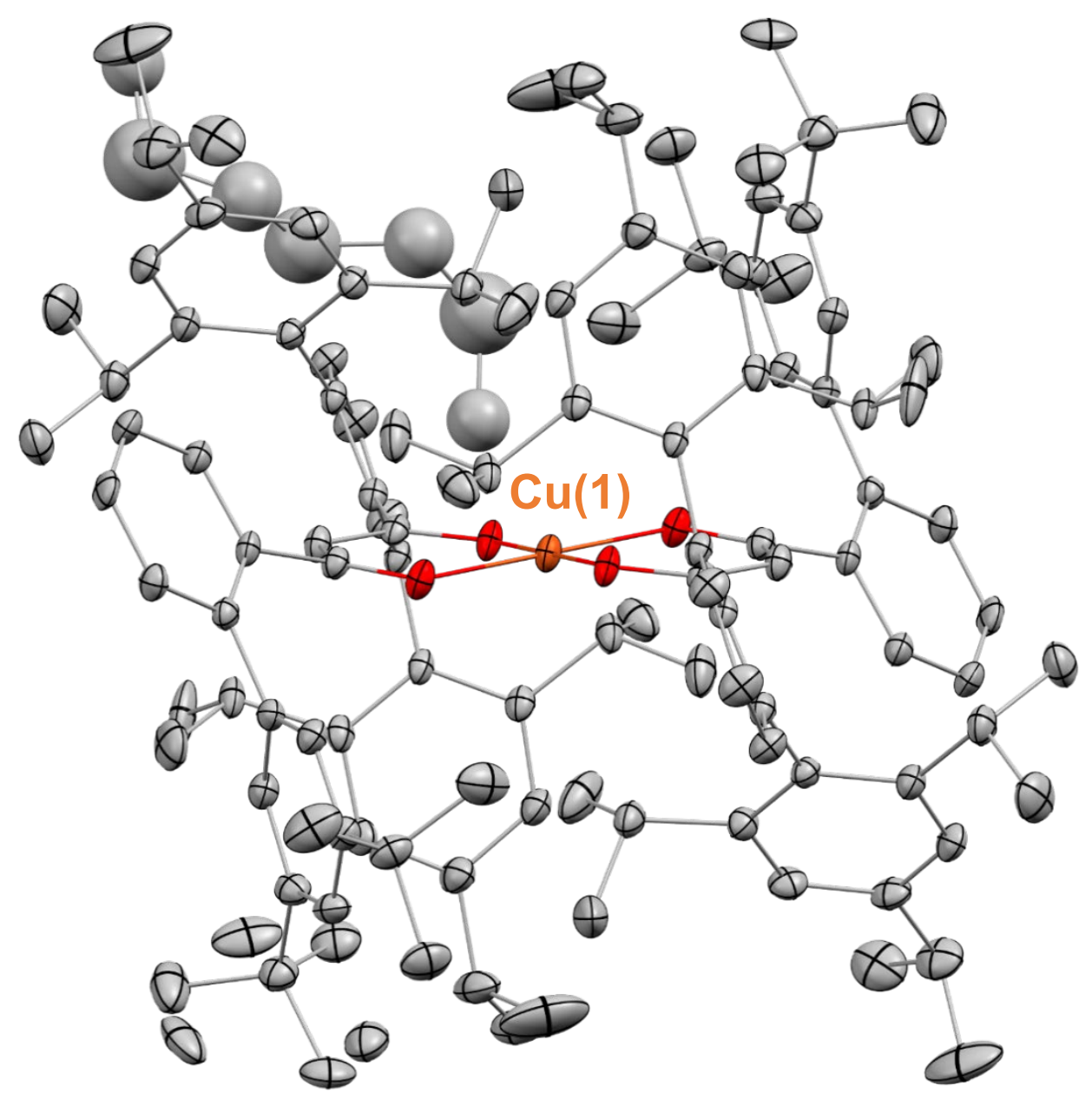

Figure S43: Thermal ellipsoid plot of 6 with ellipsoids drawn at a $50 \%$ confidence level. 


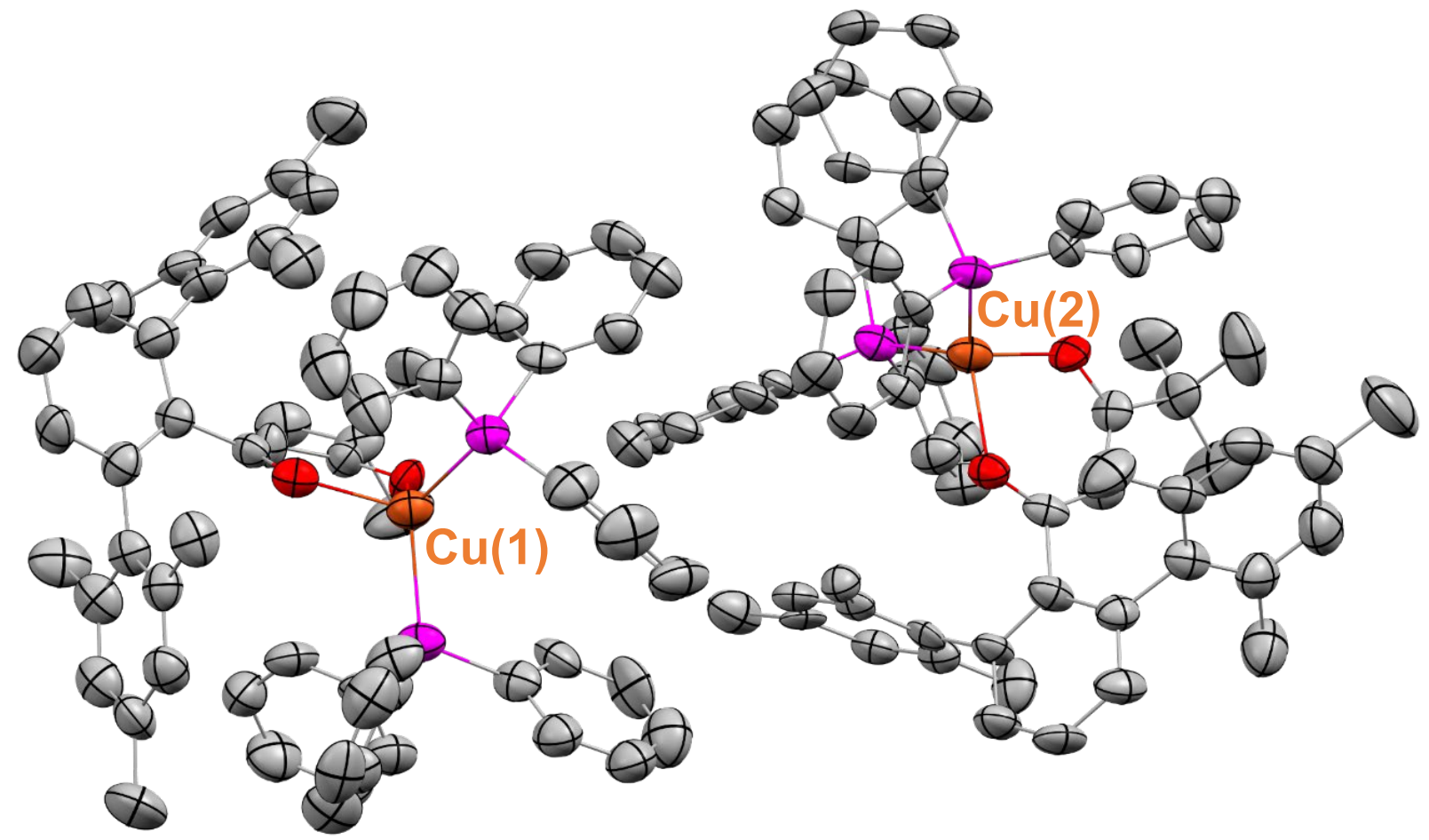

Figure S44: Thermal ellipsoid plot of 7 with ellipsoids drawn at a $50 \%$ confidence level. 


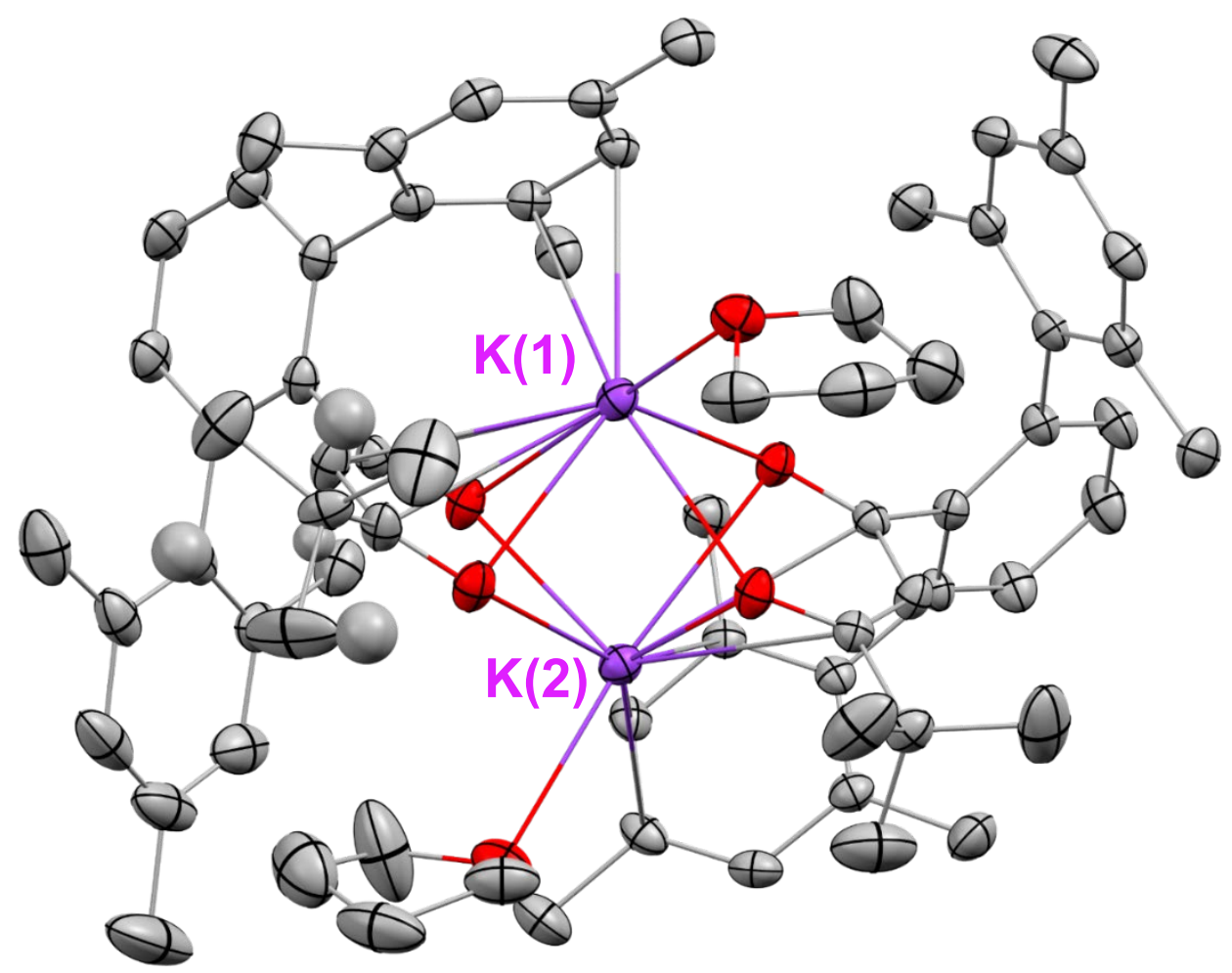

Figure S45. Thermal ellipsoid plot of $\left[\mathrm{K}\left(\mathrm{L}^{2}\right)\right]_{2}$ with ellipsoids drawn at a $50 \%$ confidence level. 
Crystallographic Details

1; Crystals were grown from a saturated solution in dichloromethane at $-20^{\circ} \mathrm{C}$. The resultant crystals were thin and plate-like, resulting in low intensity of diffraction and a high $R_{\text {int }}$ value. One tert-butyl group was found to exhibit significant disorder over two positions (60/40), and both sets of disordered atoms modeled isotropically. A single molecule of dichloromethane was located in the lattice. One of the chlorine atoms was found to be disordered over two positions (66/34) and modeled anisotropically over two positions.

3; Crystals were grown from a saturated solution in dichloromethane via slowevaporation at room temperature.

4; Crystals were grown from a saturated solution in hexanes at $-20^{\circ} \mathrm{C}$. In contrast to all other $\mathrm{CuL}_{2}$ complexes reported, no inversion symmetry is present in the complex. Two molecules of hexane with occupancies of 0.311(3) and 0.091(3) were found in the lattice, and the atoms refined isotropically. An unusually large solvent-accessible void is present, which is attributed to the steric hinderance of the aryl groups and the partial evaporation of supporting hexane molecules.

5; Crystals were grown from a saturated solution in hexanes via slow-evaporation at 2$8^{\circ} \mathrm{C}$. One well-defined molecule of hexane was in the lattice, and the atoms refined anisotropically. One tert-butyl group was found to be disordered over two positions (77/23), and both sets of disordered atoms refined anisotropically. Two inequivalent molecules of the complex are present in the asymmetric unit.

6; Crystals were grown from a saturated solution in hexanes via slow-evaporation at room temperature. A high $R_{1}$ value $(10.5 \%)$ was obtained despite reasonably strong diffraction. One tert-butyl group was found to be disordered over two positions (61/39), and both sets of disordered refined anisotropically. A disordered molecule of hexane was located in the lattice, with the positional disorder of the terminal $\mathrm{CH}_{3}$ unit modeled as a constrained 50/50 split over two positions. Additionally, the atoms in the hexane molecule were refined isotropically.

7; Crystals were grown by layering acetonitrile onto a dichloromethane solution and cooling the mixture to $-35^{\circ} \mathrm{C}$. The resultant crystals were thin and plate-like, and as is such the intensity of diffraction was weak, resulting in poor resolution and low bond length precision. The thermal ellipsoids of all carbon and oxygen atoms were restrained using the RIGU, SIMU, and ISOR commands in SHELX. Two inequivalent molecules of the complex are present in the asymmetric unit.

$\left[K\left(L^{2}\right)\right]_{2}$ dimer; Crystals were grown directly from the filtered reaction mixture of $L^{2}$ and $\mathrm{KH}$ in THF. One tert-butyl group was found to be disordered over two positions (70/30), with atoms in the major position refined anisotropically, and atoms in the minor position refined isotropically. 


\section{Crystal Tables}

\begin{tabular}{|c|c|c|c|c|}
\hline & 1 & 3 & 4 & 5 \\
\hline formula & $\mathrm{C}_{88} \mathrm{H}_{106} \mathrm{Cl}_{4} \mathrm{CuO}_{4}$ & $\mathrm{C}_{72} \mathrm{H}_{74} \mathrm{CuO}_{4}$ & $\mathrm{C}_{88.41} \mathrm{H}_{123.63} \mathrm{CuO}_{4}$ & $\mathrm{C}_{97} \mathrm{H}_{109} \mathrm{CuO}_{4}$ \\
\hline fw $(\mathrm{g} / \mathrm{mol})$ & 1433.06 & 1066.85 & 1313.98 & 1402.38 \\
\hline temperature $(\mathrm{K})$ & 105.85 & 100.0 & 100.38 & 100.01 \\
\hline cryst. syst. & monoclinic & triclinic & monoclinic & triclinic \\
\hline space group & $P 21 / c$ & $P-1$ & $\mathrm{C} 2 / \mathrm{c}$ & $\mathrm{P}-1$ \\
\hline color & green & green & green & green \\
\hline$a(\AA)$ & $14.1654(6)$ & $11.201(3)$ & $36.332(3)$ & $14.2770(8)$ \\
\hline $\mathrm{b}(\AA)$ & $13.9617(6)$ & $11.224(3)$ & $20.0255(14)$ & $14.4443(8)$ \\
\hline$c(\AA)$ & $20.2407(9)$ & $13.411(4)$ & $29.457(2)$ & $20.1443(10)$ \\
\hline$\alpha(\operatorname{deg})$ & 90 & $97.095(8)$ & 90 & 88.695(3) \\
\hline$\beta$ (deg) & $96.825(2)$ & $108.559(7)$ & $122.820(3)$ & $77.255(3)$ \\
\hline Y (deg) & 90 & 104.279(8) & 90 & $87.926(3)$ \\
\hline $\mathrm{V}\left(\AA^{3}\right)$ & $3974.7(3)$ & $1511.1(7)$ & $18011(2)$ & 4048.7(4) \\
\hline Z & 2 & 1 & 8 & 2 \\
\hline no. refl. & 53849 & 53845 & 114317 & 191799 \\
\hline unique refl. & 9104 & 9367 & 30079 & 24743 \\
\hline $\mathrm{R}_{\text {int }}$ & 0.1938 & 0.1027 & 0.0426 & 0.0679 \\
\hline R1ª (all data) & 0.1418 & 0.0921 & 0.0748 & 0.0845 \\
\hline wR2 $^{\mathrm{b}}$ (all data) & 0.1874 & 0.1484 & 0.1435 & 0.1313 \\
\hline $\mathrm{R} 1[(\mathrm{I}>2 \sigma)]$ & 0.0684 & 0.0506 & 0.0482 & 0.0493 \\
\hline$w R 2[(\mid>2 \sigma)]$ & 0.1532 & 0.1256 & 0.1277 & 0.1171 \\
\hline $\mathrm{GOF}^{\mathrm{c}}$ & 1.009 & 1.035 & 1.024 & 1.019 \\
\hline
\end{tabular}

${ }^{\mathrm{a}} \mathrm{R} 1=\frac{\sum|| \mathrm{F}_{\mathrm{o}}|-| \mathrm{F}_{\mathrm{c}}||}{\sum\left|\mathrm{F}_{\mathrm{o}}\right|},{ }^{\mathrm{b}} \mathrm{wR} 2=\sqrt{\frac{\sum \mathrm{w}\left(\mathrm{F}_{\mathrm{o}}^{2}-\mathrm{F}_{\mathrm{c}}^{2}\right)^{2}}{\sum \mathrm{w}\left(\mathrm{F}_{\mathrm{o}}^{2}\right)^{2}}},{ }^{c} \mathrm{GOF}=\sqrt{\frac{\sum \mathrm{w}\left(\mathrm{F}_{\mathrm{o}}^{2}-\mathrm{F}_{\mathrm{c}}^{2}\right)^{2}}{\mathrm{n}-\mathrm{p}}}$

Where $\mathrm{n}$ is the number of data and $\mathrm{p}$ is the number of parameters refined. 


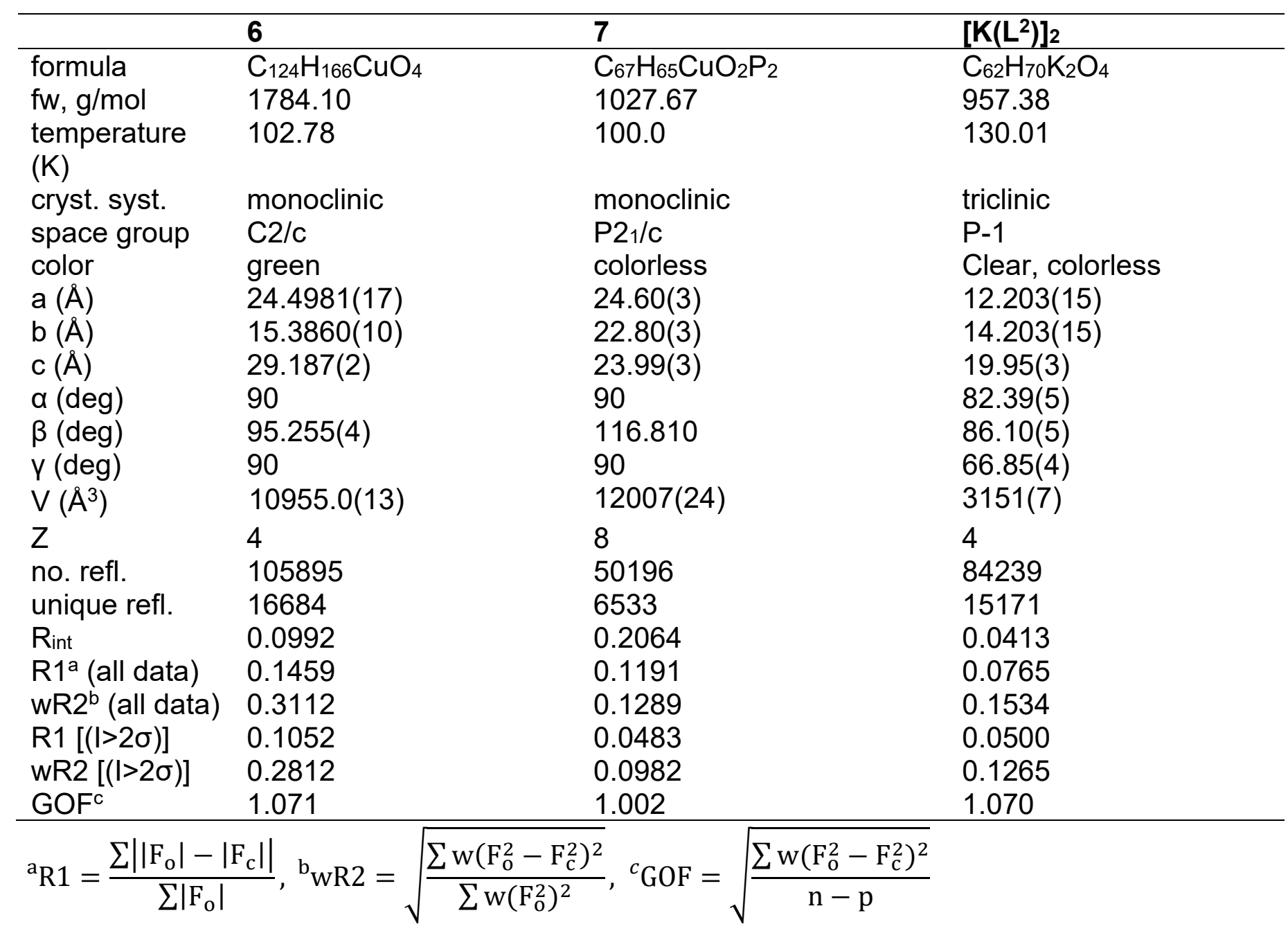

Where $\mathrm{n}$ is the number of data and $\mathrm{p}$ is the number of parameters refined. 